University of Wollongong

Research Online

Faculty of Engineering and Information

Faculty of Engineering and Information

Sciences - Papers: Part A

Sciences

$1-1-2016$

Design-oriented stress-strain model for concrete under combined FRPsteel confinement

G Lin

Hong Kong Polytechnic University

Tao Yu

University of Wollongong, taoy@uow.edu.au

Jin Guang Teng

Hong Kong Polytechnic University, cejgteng@polyu.edu.hk

Follow this and additional works at: https://ro.uow.edu.au/eispapers

Part of the Engineering Commons, and the Science and Technology Studies Commons

Research Online is the open access institutional repository for the University of Wollongong. For further information contact the UOW Library: research-pubs@uow.edu.au 


\title{
Design-oriented stress-strain model for concrete under combined FRP-steel confinement
}

\begin{abstract}
Extensive research has been conducted on fiber-reinforced polymer (FRP)-confined plain and RC columns, leading to a large number of stress-strain models. Most of these models have been developed for FRPconfined plain concrete and are thus applicable only to concrete in FRP-confined RC columns with a negligible amount of transverse steel reinforcement. The few models that have been developed for concrete under the combined confinement of FRP and transverse steel reinforcement are either inaccurate or too complex for direct use in design. This paper presents an accurate design-oriented stress-strain model for concrete under combined FRP-steel confinement in FRP-confined circular RC columns. The proposed model is formulated on the basis of extensive numerical results generated using an analysis-oriented stress-strain model recently proposed by the authors and properly captures the key characteristics of FRP-steel-confined concrete as revealed by existing test results. The model strikes a good balance between accuracy of prediction and simplicity of form and is shown to provide close predictions of test results and perform significantly better than existing stress-strain models of the same type.
\end{abstract}

\section{Keywords}

stress, strain, model, concrete, design, under, oriented, combined, frp, steel, confinement

\section{Disciplines}

Engineering | Science and Technology Studies

\section{Publication Details}

Lin, G., Yu, T. \& Teng, J. G. (2016). Design-oriented stress-strain model for concrete under combined FRPsteel confinement. Journal of Composites for Construction, 20 (4), 04015084-1-04015084-11. 


\title{
DESIGN-ORIENTED STRESS-STRAIN MODELS FOR CONCRETE UNDER COMBINED FRP-STEEL CONFINEMENT
}

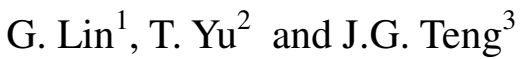

5

6

\begin{abstract}
Extensive research has been conducted on FRP-confined plain and reinforced concrete (RC) columns, leading to a large number of stress-strain models. Most of these models have been developed for FRP-confined plain concrete and are thus applicable only to concrete in FRP-confined RC columns with a negligible amount of transverse steel reinforcement. The few models that have been developed for concrete under the combined confinement of FRP and transverse steel reinforcement are either inaccurate or too complex for direct use in design. This paper presents an accurate design-oriented stress-strain model for concrete under combined FRP-steel confinement in FRP-confined circular RC columns. The proposed model is formulated on the basis of extensive numerical results generated using an analysis-oriented stress-strain model recently proposed by the authors and properly captures the key characteristics of FRP-steel-confined concrete as revealed by existing test results. The model strikes a good balance between accuracy of prediction and simplicity in form and is shown to provide close predictions of test results and perform significantly better than existing stress-strain models of the same type.
\end{abstract}

Keywords: RC column; Fiber reinforced polymer (FRP); Stress-strain model; Design; Confinement; Transverse steel reinforcement

\section{INTRODUCTION}

In the past two decades, fibre-reinforced polymer (FRP) has emerged as a popular confining material for the strengthening of existing concrete columns (Teng et al. 2002; Hollaway and Teng 2008). As a result, extensive research has been devoted to the behavior and modelling of FRP-confined concrete (FCC), mostly through axial compression tests on short FRP-confined plain concrete columns. The vast majority of the existing studies have been concerned with circular concrete columns under axial compression, in which the concrete is uniformly confined. Similarly, the scope of the present paper is limited to circular FRP-confined plain or reinforced concrete (RC) columns under axial compression.

As far as circular columns are concerned, the results of axial compression tests on short FRP-confined plain concrete columns can now be closely predicted by some of the existing stress-strain models such as those proposed by Jiang and Teng (2007) and Teng et al. (2009). These stress-strain models, however, cannot be directly used in predicting the behavior of FRP-confined RC columns (referred to as FCRC columns hereafter) when the column is provided with a significant amount of transverse steel reinforcement (TSR) . In FCRC columns, the core concrete is subjected to combined

\footnotetext{
${ }^{1} \mathrm{PhD}$ Candidate, Department of Civil and Environmental Engineering, The Hong Kong Polytechnic University, Hong Kong, China.

${ }^{2}$ Senior Lecturer, School of Civil, Mining and Environmental Engineering, Faculty of Engineering and Information Sciences, University of Wollongong, Northfields Avenue, Wollongong, NSW 2522, Australia.

${ }^{3}$ Chair Professor of Structural Engineering, Department of Civil and Environmental Engineering, The Hong Kong Polytechnic University, Hong Kong, China (Corresponding author). Email: cejgteng@polyu.edu.hk
} 
confinement from the FRP jacket and the TSR, and is referred to as FRP-steel-confined

The behavior of FSCC has received increasing research attention in recent years (Demers and Neale 1999; Pessiki et al. 2001; Li et al. 2003; Lin and Liao 2004; Carey and Harries 2005; Esfahani and Kianoush 2005; Matthys et al. 2005; Rocca 2007; Ilki et al. 2008; Eid et al. 2009; Chastre and Silva 2010; Lee et al. 2010; Wang et al. 2012; Zhang 2012), leading to several stress-strain models. Similar to those for FCC (Teng and Lam 2004), the existing stress-strain models for FSCC can be classified into two main categories: design-oriented models in closed-form expressions (e.g., Eid and Paultre 2008; Chastre and Silva 2010; Lee et al. 2010; Pellegrino and Modena 2010; Wang et al. 2012; Shirmohammadi et al. 2015) and analysis-oriented models which predict stress-strain curves using an incremental procedure (e.g., Braga et al. 2006; Megalooikonomou et al. 2012; $\mathrm{Hu}$ and Seracino 2013). Compared with analysis-oriented models, design-oriented models are particularly suitable for direct application in design calculations. By contrast, analysis-oriented models, which account explicitly for the interaction between the confining material(s) and the concrete, are more versatile and may be used to gain a better understanding of behavior and to generate numerical results for the development of a design-oriented model (Teng et al. 2009). Existing design-oriented stress-strain models for FSCC have generally been established based on the interpretation of limited experimental results available to the researchers at the time of their study. The accuracy of these models therefore depends greatly on the quality and extensiveness of the test database employed.

The present paper is concerned with the development of a new design-oriented stress-strain model for FSCC using a different methodology. This new design-oriented model is based on extensive numerical results from an accurate analysis-oriented model recently proposed by the authors (Teng et al. 2014). Teng et al.'s (2014) model is within the framework of Jiang and Teng's (2007) model for FCC but includes necessary revisions to account for the effect of TSR. With Teng et al.'s (2014) model, the stress-strain curve is generated via an incremental process that makes use of a series of stress-strain curves of actively-confined concrete at different confining pressures (Teng et al. 2014). Teng et al.'s (2014) model has been verified against a large test database and has been shown to be superior to other existing stress-strain models of the same category (i.e., Braga et al. 2006; Megalooikonomou et al. 2012; Hu and Seracino 2013) in terms of both rationality and accuracy. A similar approach has previously been employed by Teng et al. (2009) to develop a design-oriented stress-strain model for FCC (i.e., concrete confined with FRP only).

The paper begins with a description of the stress-strain behavior of FSCC as revealed by existing test results, based on which algebraic expressions for a three-segment stress-strain model is proposed. The definitions of key parameters in the proposed model are then developed on the basis of regression analyses of numerical results obtained from Teng et al.'s (2014) analysis-oriented model. Finally, the performance of the proposed model is verified against a large test database and compared with existing design-oriented stress-strain models.

It should be noted that in this paper, the term "stress-strain" represents "axial stress-axial strain" unless otherwise specified. The following sign convention is adopted: in the axial direction, compressive stresses and strains are positive but in the hoop direction, tensile stresses and strains are positive. 
95 Figure 1 shows two typical stress-strain curves of FSCC generated using Teng et al.'s 96 (2014) analysis-oriented model; the curves of the corresponding FCC and 97 steel-confined concrete (SCC) (i.e., concrete confined with steel only) generated using 98 the same model are also shown for comparison. Figure 1(a) is for a case where the FRP 99 jacket is relatively flexible, while Figure 1(b) is for a case with a relatively stiff FRP 100 jacket. Figure 1(a) shows that the curve of FSCC is very close to that of the 101 corresponding SCC when the FRP jacket is relatively flexible. In this case, the 102

103

104

105 stress-strain behavior of FSCC can be closely and conservatively predicted by an existing stress-strain model for SCC, with the contribution of FRP being ignored. Therefore, this paper is concerned mainly with cases similar to that shown in Figure 1(b) where a relatively stiff FRP jacket leads to an FSCC curve which is significantly higher than that of the corresponding SCC. With the relatively stiff FRP jacket, the curve of FCC shows a monotonically increasing bilinear shape [Figure 1(b)], which has been well established by existing research on FCC (e.g., Lam and Teng 2003; Teng et al. 2009). The threshold of FRP jacket stiffness to ensure such a bilinear stress-strain curve of FCC has been investigated by many researchers, and the following equation for the confinement stiffness ratio $\left(\rho_{K}\right)$ was proposed by Teng et al. (2009) for their model:

$$
\rho_{K}=\frac{2 E_{f} t_{f}}{D\left(f_{c o}^{\prime} / \varepsilon_{c o}\right)} \geq 0.01
$$

where $E_{f}$ and $t_{f}$ are the elastic modulus and the thickness of the FRP jacket respectively; $D$ is the diameter of the column section; $f_{c o}^{\prime}$ and $\varepsilon_{c o}$ are the compressive strength of unconfined concrete and the corresponding strain respectively. Eq. (1) is also adopted in the present study as the definition of a sufficiently stiff FRP jacket for FSCC. In the subsequent sections, FSCC refers to FSCC with a $\rho_{K}$ value not smaller than 0.01 unless otherwise specified.

It is evident from Figure 1(b) that the stress-strain curve of FSCC possesses the following characteristics: (1) it consists of two approximately linear portions connected by a curved transition portion; (2) the transition portion is significantly longer than that of the corresponding FCC; (3) the second linear portion is higher than and approximately parallel to that of the FCC. These characteristics have also been well established by the existing experimental results (Teng et al. 2014). Because of the existence of a much longer transition portion, the form of expressions used in existing design-oriented stress-strain models for FCC may not be suitable for FSCC. The expressions of Lam and Teng's stress-strain model for FCC (Lam and Teng 2003; Teng et al. 2009) are employed here to clarify this point. These expressions have been adopted in various design codes/guidelines, including the relevant Chinese standard (GB50608 2010) and the relevant design guidelines developed by the American Concrete Institute [ACI 440-08 (2008)] and the UK Concrete Society (2012). Lam and Teng's (2003) model consists of a parabolic first segment and a linear second segment, and is given by the following expressions:

$$
\sigma_{c}= \begin{cases}E_{c} \varepsilon_{c}-\frac{\left(E_{c}-E_{2}\right)^{2}}{4 f_{i}} \varepsilon_{c}^{2} & 0 \leq \varepsilon_{c}<\varepsilon_{t f} \\ f_{i}+E_{2} \varepsilon_{c} & \varepsilon_{t f} \leq \varepsilon_{c} \leq \varepsilon_{c u}\end{cases}
$$

where $\sigma_{c}$ and $\varepsilon_{c}$ are the axial stress and strain of concrete respectively; $E_{c}$ is the 
elastic modulus of concrete; $E_{2}$ is the slope of the linear second segment of the stress-strain curve; $f_{i}$ is the intercept of the stress axis by the linear second segment (referred to as the intercept stress hereafter); and $\varepsilon_{t f}$ and $f_{t f}$ are the transition strain and stress for FCC respectively.

With Lam and Teng's model, the linear second segment (i.e., a two-parameter function) is uniquely defined by the slope $E_{2}$ and the ultimate state $\left(\varepsilon_{c u}, f_{c u}^{\prime}\right)$; the parabolic first segment (i.e., a three-parameter function) as well as the transition strain and stress is uniquely defined by $E_{c}$, the condition that the two segments connect smoothly, and the implied condition that the curve passes through the origin. In Figure 2, a typical stress-strain curve of FSCC from Wang et al.'s (2012) tests is compared with the corresponding curve generated by Lam and Teng's model using the experimental values for $E_{2}, E_{c}$ and the ultimate state $\left(\varepsilon_{c u}, f_{c u}^{\prime}\right)$. It is evident from Figure 2 that a significant discrepancy exists between the two curves in the transition zone despite the good agreement of the two in terms of other parts; the strain at the starting point of the second linear portion (i.e., the transition strain) of FSCC is also seen to be significantly larger than that on the curve generated by Lam and Teng's model. It should be noted that when stress-strain curves for FSCC are discussed elsewhere in the paper, the term "transition strain" is reserved for the starting point of the second linear portion (i.e., referred to as "segment" in the models) for simplicity of presentation although another transition strain exists between the first linear portion and the curved transition portion when the whole stress-strain curve is modelled as three segments. Apparently, the expressions adopted by Lam and Teng's model cannot provide close predictions for FSCC.

\section{PROPOSED STRESS-STRAIN MODEL FOR FSCC}

\section{Algebraic Expressions for Stress-Strain Curves}

163 As shown in Figure 1(b), the stress-strain curve of FSCC generally consists of two 164 approximately linear portions connected by a curved transition portion. A review of the 165 existing stress-strain models for FSCC reveals that these models can be classified into 166 three categories: single-segment models which use a single expression to describe the entire stress-strain curve (e.g., Chastre and Silva 2010; Pellegrino and Modena 2010; Wang et al. 2012; Shirmohammadi et al. 2015), two-segment models which consist of two segments defined by two separate expressions (e.g., Li et al. 2003; Harajli 2006; Eid and Paultre 2008) and three-segment models which consist of three segments defined by three separate expressions (e.g., Lee et al. 2010). Lin et al. (2015) examined the algebraic expressions of existing models, and explored four different options for representing the stress-strain curve of FSCC based on the test results collected by them. Among the four options, the following three-segment option, which strikes a good balance between accuracy of prediction and simplicity in form, is adopted in the present study. The stress-strain curve defined by the three-segment option consists of two linear segments connected by a curved transition segment (

Figure 3) which is described by a four-parameter nth-order expression. The four-parameter expression allows the use of a predefined transition strain in determining the parameters. The three-segment model is expressed by: 


$$
\sigma_{c}= \begin{cases}E_{c} \varepsilon_{c} & \text { for } 0 \leq \varepsilon_{c}<\varepsilon_{0} \\ f_{0}+E_{c}\left(\varepsilon_{c}-\varepsilon_{0}\right)+a\left(\varepsilon_{c}-\varepsilon_{0}\right)^{n} & \text { for } \varepsilon_{0} \leq \varepsilon_{c}<\varepsilon_{t} \\ f_{t}+E_{2}\left(\varepsilon_{c}-\varepsilon_{t}\right) & \text { for } \varepsilon_{t} \leq \varepsilon_{c} \leq \varepsilon_{c u}\end{cases}
$$

where $\varepsilon_{0}$ and $f_{0}$ are the strain and the stress of the termination point of the first linear segment; $a$ and $n$ are constants and can be determined with the condition that the second segment and the third segment (also referred to as the second linear segment or final segment in the paper) are smoothly connected at the transition point $\left(\varepsilon_{t}, f_{t}\right)$ :

$$
\begin{gathered}
n=\frac{E_{2}-E_{c}}{E_{\mathrm{sec}}-E_{c}} \\
a=\frac{E_{\mathrm{sec}}-E_{c}}{\left(\varepsilon_{t}-\varepsilon_{0}\right)^{(n-1)}} \\
E_{\mathrm{sec}}=\frac{f_{t}-f_{0}}{\varepsilon_{t}-\varepsilon_{0}}
\end{gathered}
$$

The termination point of the first linear segment $\left(\varepsilon_{0}, f_{0}\right)$ is defined to be at the stress level of $\Delta f_{c s}^{\prime}$ so that this model reduces to Lam and Teng's (2003) model when there is no TSR (i.e., $\Delta f_{c s}^{\prime}=0$ ). That is,

$$
f_{0}=\Delta f_{c s}^{\prime}
$$

$$
\varepsilon_{0}=f_{0} / E_{c}
$$

There are five independent parameters in the three-segment model (i.e., $E_{2}, E_{c}, f_{i}$, $\varepsilon_{t}$, and $\varepsilon_{c u}$ ), while the transition stress, $f_{t}$, can be found from $f_{t}=f_{i}+E_{2} \varepsilon_{t}$. Among the five independent parameters, $E_{c}$ can be obtained from $E_{c}=4730 \sqrt{f_{c o}^{\prime}}\left(f_{c o}^{\prime}\right.$ in $\left.\mathrm{MPa}\right)$ following ACI 318-08 (2008); $f_{i}$ is generally taken to be equal to $f_{c o}^{\prime}$ for FCC (Lam and Teng 2003), and can thus be calculated as $f_{i}=f_{c o}^{\prime}+\Delta f_{c s}^{\prime}$ with $\Delta f_{c s}^{\prime}$ being used to account for the increase of intercept stress due to confinement from TSR. The remaining three parameters, $E_{2}, \varepsilon_{t}$, and $\varepsilon_{c u}$, as well as $\Delta f_{c s}^{\prime}$, need to be found from regression analyses of numerical results generated using Teng et al.'s (2014) analysis-oriented model and are discussed later in this paper. It should be noted that the slope of the second linear segment (i.e., the final-segment slope) in the present three-segment model (denoted by $E_{2}$ ) corresponds to that of the second segment in Lam and Teng's (2003) model for FCC.

\section{Final-Segment Slope $E_{2}$}

As discussed earlier, the second linear portion of the stress-strain curve of FSCC is approximately parallel to that of the corresponding FCC (Figure 1). Therefore, an equation capable of close predictions for the final-segment slope $\left(E_{2}\right)$ of FCC is expected to also provide close predictions for that of FSCC. In the present study, a parametric study (i.e., Parametric Study 1) was conducted using Teng et al.'s (2014) 
model on FCC to generate numerical results to derive such a predictive equation. Teng et al.'s (2014) model reduces to Jiang and Teng's (2007) model for FCC when there is no TSR. The main parameters considered in the parametric study included the unconfined concrete strength $\left(f_{c o}^{\prime}\right)$, the confinement stiffness ratio of $\operatorname{FRP}\left(\rho_{K}\right)$, and

218 the rupture strain of FRP $\left(\varepsilon_{h, \text { rup }}\right)$. The ranges of these parameters in the parametric study were selected with reference to values commonly found in laboratory tests and practical cases, which are summarized in Table 1. In the parametric study, it was assumed $\quad \varepsilon_{c o}=9.37 \times 10^{-4} \sqrt[4]{f_{c o}^{\prime}}\left(f_{c o}^{\prime}\right.$ in $\left.\mathrm{MPa}\right) \quad$ (Popovics 1973) and $E_{c}=4730 \sqrt{f_{c o}^{\prime}}\left(f_{c o}^{\prime}\right.$ in $\left.\mathrm{MPa}\right)$ (ACI 318-08 2008). The final-segment slope $\left(E_{2}\right)$ was obtained from each stress-strain curve generated in the parametric study in the following way: (1) assume that the intercept stress is equal to $f_{c o}^{\prime}$ following Lam and Teng (2003); (2) obtain the stress and strain at the ultimate state from the curve; (3) calculate $E_{2}$ as the slope of the straight line connecting the point of ultimate state and the point of intercept stress $\left(0, f_{c o}^{\prime}\right)$. Similar to the findings from numerous experimental and theoretical studies (e.g., Samaan et al. 1998; Xiao and Wu 2000; Fahmy and $\mathrm{Wu} 2010$ ), results from the parametric study showed that that the final-segment slope $\left(E_{2}\right)$ depends greatly on the FRP confinement stiffness ratio $\left(\rho_{K}\right)$ (Figure 4). The following expression is therefore proposed for $E_{2}$ for both FCC and FSCC based on a regression analysis of the results from the parametric study:

$$
\frac{E_{2}}{f_{c o}^{\prime}}=29.9 \ln \left(\rho_{K}\right)+134
$$

With Eq. (9), the threshold of $\rho_{K}$ for a positive $E_{2}$ can be obtained to be 0.0113, which is approximately the same as that proposed by Teng et al. (2009) [i.e., Eq. (1)].

\section{Increase of Intercept Stress due to TSR}

Another parametric study (i.e., Parametric Study 2) was conducted to obtain a 238 predictive equation for the increase of intercept stress due to confinement from TSR 239 (i.e., $\Delta f_{c s}^{\prime}$ in

240 Figure 3). It should be noted that $\Delta f_{c s}^{\prime}$ is different from $\Delta f_{c c, s}^{\prime *}$ in Teng et al.'s (2014) 241 model, where the latter represents the TSR contribution to the peak axial stress in the stress-strain model for active confinement adopted by Teng et al. (2014). The main parameters considered in the parametric study included the effective steel confinement stiffness $\left(K_{\text {steel }}\right)$ and the yield stress of the steel spiral/hoops $\left(f_{y h}\right)$ besides the three parameters adopted in Parametric Study 1, based on the findings from Teng et al. (2014). Following Mander et al. (1988) and Teng et al. (2014), the effective steel confinement stiffness $\left(K_{\text {steel }}\right)$ is defined by:

$$
K_{\text {steel }}=\frac{2 k_{e} E_{s} A_{s}}{s d_{s}}
$$

249 where $E_{s}, f_{y h}$, and $A_{s}$ are the elastic modulus, yield stress, and cross-sectional area 250 of a steel spiral/hoop respectively; $s$ is the vertical center-to-center spacing of steel 251 hoops or spirals; $d_{s}$ is the diameter of center line of steel spirals/hoops; and $k_{e}$ is the 252 confinement effectiveness coefficient to account for confinement non-uniformity over 253 the column height and is defined as follows: 


$$
k_{e}= \begin{cases}\left(1-\frac{s^{\prime}}{2 d_{s}}\right)^{2} /\left(1-\rho_{c c}\right) & \text { for circular hoops } \\ \left(1-\frac{s^{\prime}}{2 d_{s}}\right) /\left(1-\rho_{c c}\right) & \text { for circular spirals }\end{cases}
$$

255 where $s^{\prime}$ is the clear vertical spacing of steel spirals/hoops $\left(s^{\prime}=s-d_{s}\right)$ and $\rho_{c c}$ is the 256 ratio of cross-sectional area between the longitudinal steel reinforcement and the 257 enclosed concrete core.

With the definition of $K_{\text {steel }}$, the effective confining pressure from TSR after the yielding of TSR can be calculated as

$$
f_{l s, y}^{\prime}=K_{\text {steel }} \varepsilon_{y}=\frac{K_{\text {steel }} f_{y h}}{E_{s}}
$$

where $\varepsilon_{y}$ is the yield strain of steel spirals/hoops.

The ranges for the parameters covered in the parametric study are also summarized in

Table 1. The increase of intercept stress due to confinement from TSR (i.e., $\Delta f_{c s}^{\prime}$ ) was obtained from each stress-strain curve generated in the parametric study in the following way: (1) obtain the stress and strain at the ultimate state from the curve; (2) obtain the intercept stress, $f_{i}$, as the intercept of the stress axis by the straight line which has a slope of $E_{2}$ calculated from Eq. (9) and passes through the point of ultimate state; (3) find $\Delta f_{c s}^{\prime}$ by $\Delta f_{c s}^{\prime}=f_{i}-f_{c o}^{\prime}$. It should be noted that although most of the stress-strain curves generated in the parametric study have a shape similar to that shown in Figure 1(b), a small fraction of the curves does not have the linear final portion (Figure 5). This happens when the confinement from the TSR is very low and/or the rupture strain of FRP is relatively small so that the ultimate state (i.e., FRP rupture) is reached before the yielding of TSR. These curves were identified by comparing the slope of the stress-strain curve at the ultimate state and the $E_{2}$ value of the corresponding FCC, and were excluded when calculating $\Delta f_{c s}^{\prime}$.

The results from the parametric study indicate that $\Delta f_{c s}^{\prime}$ depends greatly on the effective steel confinement ratio $\left(f_{l s, y}^{\prime} / f_{c o}^{\prime}\right)$ and the confinement stiffness ratio between FRP and TSR $\left(\rho_{f}=K_{f r p} / K_{\text {steel }}\right)$. To propose a rational expression for $\Delta f_{c s}^{\prime}$, the following two extreme conditions were considered: (1) when no TSR is present, $\Delta f_{c s}^{\prime}$ should be equal to zero; (2) as $\Delta f_{c s}^{\prime}$ basically represents the increase of strength due to confinement of TSR, its expression may be so selected that it reduces to an accurate existing equation for the peak stress of SCC when there is no FRP jacket (i.e., $\rho_{f}=0$ ).

Given the above considerations, the following equation is proposed:

$$
\frac{\Delta f_{c s}^{\prime}}{f_{c o}^{\prime}}=3.12\left[\frac{f_{l s, y}^{\prime}}{f_{c o}^{\prime}\left(1+a \rho_{f}^{b}\right)}\right]^{0.736}
$$

289 Eq. (13) provides accurate predictions of the axial stress of SCC when $\rho_{f}=0$ (Teng

290 et al. 2014). A regression analysis was conducted to minimize the errors between the 291 predictions of Eq. (13) and the results from the parametric study (i.e., Parametric Study 


$$
\frac{\Delta f_{c s}^{\prime}}{f_{c o}^{\prime}}=3.12\left[\frac{f_{l s, y}^{\prime}}{f_{c o}^{\prime}\left(1+7.07 \rho_{f}^{1.60}\right)}\right]^{0.736}
$$

\section{Transition Strain}

296 The transition strain $\left(\varepsilon_{t}\right)$ is the strain at the starting point of the second linear portion of the stress-strain curve of FSCC. The second linear portion is governed mostly by the confinement stiffness of FRP, which means that the confinement effect of TSR becomes negligible after the transition strain. Therefore, it is reasonable to expect that the transition strain is approximately equal to the strain at the peak stress of SCC $\left(\varepsilon_{c c}\right)$ when the confinement stiffness of FRP is not too large. This is also evident from the experimental results from a number of studies on FSCC (Carey and Harries 2005; Matthys et al. 2005; Eid et al. 2009; Chastre and Silva 2010; Wang et al. 2012). The strain at the peak stress of SCC ( $\left.\varepsilon_{c c}\right)$ can be predicted by a model for actively confined concrete (which can closely approximate the response of SCC after the yielding of TSR) such as the model proposed by Jiang and Teng (2007):

$$
\frac{\varepsilon_{c c}}{\varepsilon_{c o}}=1+3.89\left(\frac{f_{c c}^{\prime}}{f_{c o}^{\prime}}-1\right)^{1.2}
$$

308 where $f_{c c}^{\prime}$ is the peak stress of SCC.

In addition, the transition strain of FSCC should reduce to that of FCC when there is no TSR. Based on these considerations, the following equation is proposed for the 312 transition strain $\left(\varepsilon_{t}\right)$ of FSCC:

314 where

$$
\frac{\varepsilon_{t}}{\varepsilon_{t f}}=1+3.89\left(\frac{\Delta f_{c s}^{\prime}}{f_{c o}^{\prime}}\right)^{1.2}
$$

317 Eq. (16) means that $\varepsilon_{t}$ is equal to the transition strain of FCC, $\varepsilon_{t f}$, when there is no

318 TSR ( $\Delta f_{c s}^{\prime}$ is equal to zero) and the transition strain $\varepsilon_{t}$ increases with the confinement 319 stiffness of FRP, which is consistent with the test results of FSCC (e.g., Eid et al. 2009; 320 Wang et al. 2012). Moreover, as $\varepsilon_{t f}$ is very close to $\varepsilon_{c o}$ when the confinement 321 stiffness of FRP is not too large, Eq. (16) implies that $\varepsilon_{t}$ is approximately equal to $322 \varepsilon_{c c}$ in Eq. (15).

\section{Ultimate State}

324 The ultimate state of FSCC is reached when the FRP jacket ruptures due to hoop 325 tension (i.e., when the hoop strain of FRP reaches its rupture strain). Teng et al. (2014) 326 proposed the following axial strain-FRP hoop strain relationship for FSCC: 


$$
\frac{\varepsilon_{c}}{\varepsilon_{c o}}=0.85\left(1+8 \frac{f_{l f}}{f_{c o}^{\prime}}+\alpha \frac{f_{l s}^{\prime}}{f_{c o}^{\prime}}\right)\left\{\left[1+0.75\left(\frac{\varepsilon_{h}}{\varepsilon_{c o}}\right)\right]^{0.7}-\exp \left[-7\left(\frac{\varepsilon_{h}}{\varepsilon_{c o}}\right)\right]\right\}
$$

$$
\alpha=1.59+15.1 \rho_{f}
$$

330 With this relationship, the ultimate strain of FSCC $\left(\varepsilon_{c u}\right)$ can be calculated by equating

the FRP hoop strain $\left(\varepsilon_{h}\right)$ to the hoop rupture strain of $\operatorname{FRP}\left(\varepsilon_{h, \text { rup }}\right)$ :

$$
\frac{\varepsilon_{c u}}{\varepsilon_{c o}}=0.85\left(1+8 \frac{f_{l f, r u p}}{f_{c o}^{\prime}}+\alpha \frac{f_{l s, r u p}^{\prime}}{f_{c o}^{\prime}}\right)\left\{\left[1+0.75\left(\frac{\varepsilon_{h, r u p}}{\varepsilon_{c o}}\right)\right]^{0.7}-\exp \left[-7\left(\frac{\varepsilon_{h, r u p}}{\varepsilon_{c o}}\right)\right]\right\}
$$

where $f_{l f, r u p}$ and $f_{l s, \text { rup }}^{\prime}$ are the confining pressures from FRP and TSR at the ultimate state respectively. $f_{l s, \text { rup }}^{\prime}$ can in principle be replaced by $f_{l s, y}^{\prime}$ as long as the yield strain of TSR is smaller than the hoop rupture strain of the FRP jacket.

Eq. (20), however, is too complex for direct use in practical design. To simplify Eq. (33), the expression within the curly bracket on the right side of this equation is shown against $\varepsilon_{h, r u p} / \varepsilon_{c o}$ in Figure 7 . It is evident from Figure 7 that the curve becomes

almost linear when $\varepsilon_{h, \text { rup }} / \varepsilon_{c o}$ exceeds around 0.5 (or when $\varepsilon_{h, \text { rup }}$ exceeds around $0.1 \%$ ). This observation allows the use of a linear function to replace the complex expression within the curly bracket, considering that the rupture strain of commonly used FRP (e.g., carbon FRP and glass FRP) is much larger than $0.1 \%$. The following equation is therefore proposed to replace Eq. (33):

$$
\frac{\varepsilon_{c u}}{\varepsilon_{c o}}=0.85\left(1+8 \frac{f_{l f, r u p}}{f_{c o}^{\prime}}+\alpha \frac{f_{l s, \mathrm{y}}^{\prime}}{f_{c o}^{\prime}}\right)\left[1+0.465\left(\frac{\varepsilon_{h, r u p}}{\varepsilon_{c o}}\right)\right]
$$

Eq. (21) can be rewritten as:

$$
\frac{\varepsilon_{c u}}{\varepsilon_{c o}}=\phi\left(f_{l f, r u p}, \varepsilon_{h, r u p}\right)+0.85 \alpha \frac{f_{l s, y}^{\prime}}{f_{c o}^{\prime}}\left(1+0.465 \rho_{\varepsilon}\right)
$$

where $\phi\left(f_{l f, \text { rup }}, \varepsilon_{h, \text { rup }}\right)$ is a function of $f_{l f, \text { rup }}$ and $\varepsilon_{h, \text { rup }}$. Apparently, Eq. (22) reduces to the following equation for FCC:

$$
\frac{\varepsilon_{c u}}{\varepsilon_{c o}}=\phi\left(f_{l f, r u p}, \varepsilon_{h, r u p}\right)
$$

To retain consistency with the equation proposed by Teng et al. (2009) for the ultimate strain of FCC, $\phi\left(f_{l f, \text { rup }}, \varepsilon_{h, \text { rup }}\right)$ is replaced by the corresponding expression in Teng et al.'s (2009) model, and Eq. (22) becomes:

$$
\frac{\varepsilon_{c u}}{\varepsilon_{c o}}=1.75+6.5 \rho_{K}^{0.80} \rho_{\varepsilon}^{1.45}+0.85 \alpha \frac{f_{l s, y}^{\prime}}{f_{c o}^{\prime}}\left(1+0.465 \rho_{\varepsilon}\right)
$$

The predictions of Eq. (24) are compared with those of Eq. (20) in Figure 8 for all the numerical cases in Table 1; close agreement can be seen between the two.

361 The ultimate strain $\varepsilon_{c u}$ is normally larger than the transition strain $\varepsilon_{t}$ calculated by 362 Eq.(16), except for cases where the confinement from TSR is very high and/or the rupture strain of FRP is relatively small (Figure 5). 
When $\varepsilon_{c u}>\varepsilon_{t}$, Eqs. (9), (14), (16), and (24), which are for $E_{2}, \Delta f_{c s}^{\prime}, \varepsilon_{t}$ and $\varepsilon_{c u}$ respectively, can be employed together with Eq. (3) to define the proposed model to predict the stress-strain response. In the rare case where $\varepsilon_{c u} \leq \varepsilon_{t}$, the final segment does not exist, so the proposed model only has two segments (i.e., the first two segments) with the second one terminating at a strain of $\varepsilon_{c u}$. Nevertheless, for the latter case, Eqs. (9) and (14) for $E_{2}$ and $\Delta f_{c s}^{\prime}$ still need to be used to define the virtual final segment so that $f_{t}$ can be found and used together with $\varepsilon_{t}$ to define the first segment or the first two segments. The ultimate stress $f_{c u}^{\prime}$ can be easily found from $\varepsilon_{c u}$.

It should also be noted that the proposed model is different from most existing stress-strain models (e.g., Lam and Teng 2003; Teng et al. 2009) for FCC or FSCC in the determination of $E_{2}$. In the existing models (e.g., Lam and Teng 2003; Teng et al. 2009), $E_{2}$ is calculated using the point of ultimate state $\left(\varepsilon_{c u}, f_{c u}^{\prime}\right)$ and the point of intercept stress $\left(0, f_{i}\right)$. The main disadvantage of such models is that they predict different stress-strain paths for the same concrete confined with an FRP jacket of the same hoop stiffness but different FRP rupture strains $\left(\varepsilon_{h, \text { rup }}\right)$. Although these differences are small in practical cases, they are conceptually in disagreement with the understanding that the stiffness instead of the hoop rupture strain of the FRP jacket determines the stress-strain path. The advantage of such models is that they provide an explicit definition of the ultimate state, which is convenient in section analysis and member design. The proposed stress-strain model overcomes this drawback by ensuring that $E_{2}$ of the stress-strain curve is directly related to the stiffness of the FRP jacket. The proposed stress-strain model therefore may be referred to as a stiffness-based stress-strain model which is superior in cases where the correct prediction of stress-strain paths is of greater importance (e.g., seismic response analysis).

\section{PERFORMANCE OF THE PROPOSED MODEL}

\section{Test Database}

The test database of the present study consists of 48 FCRC specimens. It includes all the test data collected by Teng et al. (2014) from the studies of Demers and Neale (1999), Pessiki et al. (2001), Eid et al. (2009), Chastre and Silva (2010), Wang et al. (2012) and Zhang (2012), and results of another 5 FCRC specimens tested by Matthys et al. (2005). The 5 FCRC specimens of Matthys et al. (2005) had a diameter of 400 $\mathrm{mm}$ and covered the ranges of parameters as follows: $f_{c o}^{\prime}=29.2 \sim 33.4 \mathrm{MPa}$, $f_{l s, y}^{\prime} / f_{c o}^{\prime}=0.0225 \sim 0.0258 \quad, \quad K_{\text {steel }} / f_{c o}^{\prime}=8.03 \sim 9.20 \quad, \quad \rho_{K}=0.0121 \sim 0.149 \quad$, $\rho_{\varepsilon}=1.15 \sim 3.33$. Matthys et al. (2005) provided only the axial stress-axial strain curves of these specimens (i.e., no axial stress-lateral strain curves), so they were not included in Teng et al.'s (2014) database. All the FRP-confined specimens were wrapped with an FRP jacket with fibers oriented in the hoop direction only via a wet lay-up process; 13 specimens tested by Eid et al. (2009) were reinforced with steel 
spirals while the other specimens were reinforced with steel hoops.

The majority of the specimens in the database are medium- to large-scale specimens with the diameter being not smaller than $250 \mathrm{~mm}$ (up to $508 \mathrm{~mm}$ ). It has been widely reported that the unconfined strength of concrete $\left(f_{c o}^{\prime}\right)$ in columns of such a scale may be significantly lower than that found from standard concrete cylinder tests (i.e., $f_{c}^{\prime}$ ) using $150 \mathrm{~mm} \times 300 \mathrm{~mm}$ cylinders, although the difference between $f_{c o}^{\prime}$ and $f_{c}^{\prime}$ varies and is somewhat uncertain (Park and Paulay 1975; Demers and Neale 1999; Chastre and Silva 2010; De Luca et al. 2010; Zhang 2012). In the present study, $f_{c o}^{\prime}$ is taken to be $0.85 f_{c}^{\prime}$ following ACI 318 (2008) for all the specimens except the specimens presented in Pessiki et al. (2001), Chastre and Silva (2010) and Wang et al. (2012) where FCC columns with the same dimensions as the corresponding FCRC columns were tested; for these specimens, $f_{c o}^{\prime}$ was back-calculated from the test results of FCC columns using Jiang and Teng's (2007) model. The same method of determining $f_{c o}^{\prime}$ has also been adopted by Teng et al. (2014) and other researchers (e.g., Saatcioglu and Razvi 1992).

\section{Increase of Intercept Stress due to TSR $\Delta f_{c s}^{\prime}$}

The experimental value of $\Delta f_{c s}^{\prime}$ can be obtained as $\Delta f_{c s}^{\prime}=f_{i}-f_{c o}^{\prime}$, where the intercept stress $f_{i}$ can be extracted from the experimental stress-strain curve. The so-obtained $\Delta f_{c s}^{\prime}$ values of all the 48 FCRC specimens are shown in Figure 9 against the curve depicted by Eq. (14). It is evident that Eq. (14) generally provides reasonably close predictions of the test results for a wide range of effective steel confinement ratios. A relatively large scatter exists for FSCC with a low effective steel confinement ratio, which is believed to be at least partially due to the use of $f_{c o}^{\prime}$ as the intercept stress of FCC.

\section{Stress-Strain Curves}

The predictions of the proposed model are compared with typical test results from Eid et al. (2009) and Wang et al. (2012) in Figure 10. The predictions of existing design-oriented models proposed by Harajli (2006), Eid and Paultre (2008), Pellegrino and Modena (2010), and Wang et al. (2012) are also shown in Figure 10 for comparison. As mentioned earlier, the first two of these existing models are typical single-segment stress-strain models while the last two are typical two-segment stress-strain models. Among these models, the ones proposed by Harajli (2006), Pellegrino and Modena (2010) and Wang et al. (2012) are for the average axial stress-strain behavior of the concrete in the entire section. These models ignore the clear difference between the core concrete (i.e., FSCC) and the cover concrete which is subjected to FRP confinement only (i.e., FCC), which is a significant disadvantage as in column analysis the cover and the core parts of the section are typically separately treated. To make the comparison with these models possible, the average stress of concrete in an FCRC column instead of the stress of the core concrete (i.e., FSCC) is used in Figures 10 and 11. The experimental average axial stress of concrete in an FCRC column was calculated using the following equation:

$$
\sigma_{c, a v g}=\frac{P_{c}-P_{s}}{A_{g}-A_{s}}
$$


where $P_{c}$ is the total axial load carried by the column; $P_{s}$ is the axial load carried by the longitudinal steel bars; $A_{g}$ is the gross area of the column section; and $A_{s}$ is the total area of the longitudinal steel bars. For models which predict different axial stresses for the core concrete and the cover concrete (e.g., the models proposed in the present study), the average axial stress of the entire section was calculated as follows:

$$
\sigma_{c, a v g}=\frac{\sigma_{\text {core }} A_{\text {core }}+\sigma_{\text {cover }} A_{\text {cover }}}{A_{\text {core }}+A_{\text {cover }}}
$$

where $\sigma_{\text {core }}$ and $A_{\text {core }}$ are the axial stress and area of the core concrete (excluding the area of longitudinal steel bars) respectively; and $\sigma_{\text {cover }}$ and $A_{\text {cover }}$ are the axial stress

and area of the cover concrete respectively. The experimental hoop rupture strain of $\operatorname{FRP}\left(\varepsilon_{h, \text { rup }}\right)$ was used to find the ultimate axial strain for all the models.

It is obvious from Figure 10 that the model proposed by Pellegrino and Modena (2010) fails to provide accurate predictions of the test results. Harajli's (2006) model provides reasonable but not accurate predictions of the results presented by Eid et al. (2009), and significantly underestimates the ultimate strain of the specimens tested by Wang et al. (2012). Wang et al.'s (2012) model performs well for their own specimens, but fails to predict the test results presented by Eid et al. (2009) especially in terms of the ultimate strain. Eid and Paultre's (2008) model appears to be the most accurate among the existing models, but this model becomes inaccurate for specimens with a relatively high effective steel confinement ratio [Figure $10(\mathrm{e})-(\mathrm{g})$ ]. It is evident from Figure 10 that the proposed model provides accurate predictions of all the test results, and performs significantly better than all the existing models.

Figure 11 shows a comparison for FSCC in four FCRC specimens tested by Lee et al. (2010) which were reinforced with steel spirals of very high yield strength (i.e., 1200 MPa). Lee et al.'s (2010) specimens were not used in the development of the model of Teng et al. (2014) as the hoop strain data from this study were questionable (Teng et al. 2014). As a result, the predictions are terminated at the experimental ultimate axial strain for all the models in Figure 11. It can be seen again that the proposed model performs much better than all the existing models. The proposed model however slightly overestimates the axial stress over the transition portion as the confining pressure from the steel spirals after yielding is directly used in calculating the transition strain defined by Eq. (16), but in reality this confining pressure had to increase gradually from zero to the value at yielding. This issue is not so significant for TSR with a much lower yield stress.

486 Figure 12 shows the comparison for ultimate axial strains for all the 48 FCRC 487 specimens, while the comparison for ultimate axial stresses is shown in Figure 13. It is 488 evident that the proposed model provides accurate predictions of the ultimate state of

\section{CONCLUSIONS}

492 This paper has presented a three-segment design-oriented stress-strain model for 493 FRP-steel-confined concrete (FSCC) in FRP-confined circular RC columns. The 494 proposed model has been formulated on the basis of extensive numerical results 
generated using an accurate analysis-oriented stress-strain model recently proposed by the authors as well as the key characteristics of FSCC as revealed by test results. It consists of a linear initial segment, a curved transition segment, and a linear final segment; the transition segment is smoothly connected to both the initial segment and the final segment. The proposed model reduces to Lam and Teng's well-known stress-strain model for FRP-confined concrete (Lam and Teng 2003; Teng et al. 2009) when no confinement from transverse steel exists. The proposed model has been shown to provide accurate predictions of test results and perform significantly better than existing stress-strain models of the same type. The proposed model strikes a good balance between accuracy of prediction and simplicity in form, and its algebraic expressions allow much simpler mathematical manipulations (e.g., differentiations and integrations) than those of the existing models.

It is worth noting that the present paper has been focused on the development of a stress-strain model for FSCC in columns under monotonic concentric axial compression. The extension of the model for use in columns subjected to combined axial compression and bending or cyclic loading is an important subject for future research.

\section{ACKNOWLEDGMENTS}

The authors are grateful for the financial support received from the Research Grants Council of the Hong Kong Special Administrative Region (Project No: PolyU 152153/14E), the National Basic Research Program (i.e., 973 Program) (Project Number: 2012CB026200) as well as the Australian Research Council through a Discovery Early Career Researcher Award (Project ID: DE140101349) for the second author.

\section{REFERENCES}

ACI 318-08 (2008). Building Code Requirements for Structural Concrete and Commentary, American Concrete Institute, Farmington Hills, Michigan, USA.

ACI 440-08 (2008). Guide for the Design and Construction of Externally Bonded FRP Systems for Strengthening Concrete Structures, American Concrete Institute, Farmington Hills, Michigan, USA.

Braga, F., Gigliotti, R. and Laterza, M. (2006). “Analytical stress-strain relationship for concrete confined by steel stirrups and/or FRP jackets", Journal of Structural Engineering, ASCE, Vol. 132, No. 9, pp. 1402-1416.

Carey, S.A. and Harries, K.A. (2005). “Axial behavior and modeling of confined small-, medium-, and large-scale circular sections with carbon fiber-reinforced polymer jackets”, ACI Structural Journal, Vol. 102, No. 4, pp. 596-604.

Chastre, C. and Silva, M.A. (2010). "Monotonic axial behavior and modelling of RC circular columns confined with CFRP”, Engineering Structures, Vol. 32, No. 8, pp. 2268-2277.

Concrete Society (2012). Design Guidance for Strengthening Concrete Structures 

Crowthorne, Berkshire, U.K.

De Luca, A., Nardone, F., Matta, F., Nanni, A., Lignola, G.P. and Prota, A. (2010). "Structural evaluation of full-scale FRP-confined reinforced concrete columns", Journal of Composites for Construction, ASCE, Vol. 15, No. 1, pp. 112-123.

Demers, M. and Neale, K.W. (1999). "Confinement of reinforced concrete columns with fibre-reinforced composite sheets-an experimental study", Canadian Journal of Civil Engineering, Vol. 26, No. 2, pp. 226-241.

Eid, R. and Paultre, P. (2008). "Analytical model for FRP-confined circular reinforced concrete columns", Journal of Composites for Construction, ASCE, Vol. 12, No. 5, pp. 541-552.

Eid, R., Roy, N. and Paultre, P. (2009). "Normal- and high-strength concrete circular elements wrapped with FRP composites", Journal of Composites for Construction, ASCE, Vol. 13, No. 2, pp. 113-124.

Esfahani, M. and Kianoush, M. (2005). "Axial compressive strength of reinforced concrete columns wrapped with FRP”, International Journal of Engineering Transactions B: Applications, Vol. 18, No. 1, pp. 9-19.

Fahmy, M.F.M. and Wu, Z. (2010). "Evaluating and proposing models of circular concrete columns confined with different FRP composites", Composites Part B: Engineering, Vol. 41, No. 3, pp. 199-213.

GB-50608 (2010). Technical Code for Infrastructure Application of FRP Composites, Code of China, China Planning Press, Beijing, China.

Harajli, M.H. (2006). “Axial stress-strain relationship for FRP confined circular and rectangular concrete columns", Cement and Concrete Composites, Vol. 28, No. 10, pp. 938-948.

Hollaway, L.C. and Teng, J.G. (2008). Strengthening and Rehabilitation of Civil Infrastructures Using Fibre-Reinforced Polymer (FRP) Composites, Woodhead Publishing, Cambridge, UK.

Hu, H. and Seracino, R. (2013). “Analytical model for FRP-and-steel-confined circular concrete columns in compression", Journal of Composites for Construction, ASCE, Vol. 18, No. 3, pp. A4013012.

Ilki, A., Peker, O., Karamuk, E., Demir, C. and Kumbasar, N. (2008). "FRP retrofit of low and medium strength circular and rectangular reinforced concrete columns", Journal of Materials in Civil Engineering, ASCE, Vol. 20, No. 2, pp. 169-188.

Jiang, T. and Teng, J.G. (2007). “Analysis-oriented stress-strain models for 

FRP-confined concrete", Engineering Structures, Vol. 29, No. 11, pp. 2968-2986.

575

576

577

578

579

580

581

582

583

Lam, L. and Teng, J.G. (2003). "Design-oriented stress-strain model for FRP-confined concrete", Construction and Building Materials, Vol. 17, No. 6, pp. 471-489.

Lee, J.Y., Yi, C.K., Jeong, H.S., Kim, S.W. and Kim, J.K. (2010). "Compressive response of Concrete confined with Steel Spirals and FRP Composites", Journal of Composite Materials, Vol. 44, No. 4, pp. 481-504.

Li, Y.F., Lin, C.T. and Sung, Y.Y. (2003). "A constitutive model for concrete confined with carbon fiber reinforced plastics", Mechanics of Materials, Vol. 35, No. 3, pp. 603-619.

Lin, G., Yu, T. and Teng, J.G. (2015). "On the representation of stress-strain behaviour of concrete under combined FRP and steel confinement", 12th International Symposium on Fiber Reinforced Polymers for Reinforced Concrete Structures (FRPRCS-12) \& 5th Asia-Pacific Conferenceon Fiber Reinforced Polymers in Structures (APFIS-2015), 14-16 December, Nanjing, China.

Lin, H.J. and Liao, C.I. (2004). "Compressive strength of reinforced concrete column confined by composite material", Composite Structures, Vol. 65, No. 2, pp. 239-250.

Mander, J.B., Priestley, M.J. and Park, R. (1988). "Theoretical stress-strain model for confined concrete", Journal of Structural Engineering, ASCE, Vol. 114, No. 8, pp. 1804-1826.

Matthys, S., Toutanji, H., Audenaert, K. and Taerwe, L. (2005). “Axial load behavior of large-scale columns confined with fiber-reinforced polymer composites", ACI Structural Journal, Vol. 102, No. 2, pp. 258-267.

Megalooikonomou, K.G., Monti, G. and Santini, S. (2012). "Constitutive Model for Fiber-Reinforced Polymer-and Tie-Confined Concrete", ACI Structural Journal, Vol. 109, No. 4, pp. 569.

Park, R. and Paulay, T. (1975). Reinforced Concrete Structures, Wiley, New York, USA.

Pellegrino, C. and Modena, C. (2010). “Analytical model for FRP confinement of concrete columns with and without internal steel reinforcement", Journal of Composites for Construction, ASCE, Vol. 14, No. 6, pp. 693-705.

Pessiki, S., Harries, K.A., Kestner, J.T., Sause, R. and Ricles, J.M. (2001). “Axial behavior of reinforced concrete columns confined with FRP jackets", Journal of Composites for Construction, ASCE, Vol. 5, No. 4, pp. 237-245.

Popovics, S. (1973). "A numerical approach to the complete stress-strain curve of 

concrete", Cement and Concrete Research, Vol. 3, No. 5, pp. 583-599.

Rocca, S. (2007). Experimental and Analytical Evaluation of FRP-Confined Large Size Reinforced Concrete Columns, Ph.D. thesis, Civil Engineering, University of Missouri, Rolla, Missouri, USA.

Saatcioglu, M. and Razvi, S.R. (1992). "Strength and ductility of confined concrete", Journal of Structural Engineering, ASCE, Vol. 118, No. 6, pp. 1590-1607.

Samaan, M., Mirmiran, A. and Shahawy, M. (1998). "Model of concrete confined by fiber composites", Journal of Structural Engineering, ASCE, Vol. 124, No. 9, pp. 1025-1031.

Teng, J.G., Chen, J.F., Smith, S.T. and Lam, L. (2002). FRP Strengthened RC Structures, John Wiley \& Sons, West Sussex, UK.

Teng, J.G., Jiang, T., Lam, L. and Luo, Y.Z. (2009). "Refinement of a design-oriented stress-strain model for FRP-confined concrete", Journal of Composites for Construction, ASCE, Vol. 13, No. 4, pp. 269-278.

Teng, J.G. and Lam, L. (2004). "Behavior and modeling of fiber reinforced polymer-confined concrete", Journal of Structural Engineering, ASCE, Vol. 130, No. 11, pp. 1713-1723.

Teng, J.G., Lin, G. and Yu, T. (2014). “Analysis-oriented stress-strain model for concrete under combined FRP-steel confinement", Journal of Composites for Construction, ASCE, 10.1061/(ASCE)CC.1943-5614.0000549, pp. 04014084.

Wang, Z., Wang, D., Smith, S.T. and Lu, D. (2012). "Experimental testing and analytical modeling of CFRP-confined large circular RC columns subjected to cyclic axial compression”, Engineering Structures, Vol. 40, No., pp. 64-74.

Xiao, Y. and Wu, H. (2000). "Compressive behavior of concrete confined by carbon fiber composite jackets", Journal of Materials in Civil Engineering, ASCE, Vol. 
Table 1 Parameters used in the parametric study

\begin{tabular}{|c|c|c|c|c|}
\hline Concrete & \multicolumn{2}{|c|}{ FRP Jacket } & \multicolumn{2}{|c|}{ Transverse Steel $^{*}$} \\
\hline $\begin{array}{l}\text { Compressive } \\
\text { strength } \\
f_{c o}^{\prime} \quad(\mathrm{MPa})\end{array}$ & $\begin{array}{c}\text { Confinement } \\
\text { stiffness ratio } \\
\rho_{K}\end{array}$ & $\begin{array}{c}\text { Rupture } \\
\text { strain } \\
\varepsilon_{h, \text { rup }}\end{array}$ & $\begin{array}{c}\text { Effective } \\
\text { confinement } \\
\text { stiffness ratio } \\
K_{\text {steel }} / f_{c o}^{\prime}\end{array}$ & $\begin{array}{l}\text { Yield stress } \\
f_{y h} \quad(\mathrm{MPa})\end{array}$ \\
\hline $\begin{array}{l}20-50 \text { at an } \\
\text { interval of } 10\end{array}$ & $\begin{array}{c}0.01-0.15 \text { at } \\
\text { an interval of } \\
0.005\end{array}$ & $\begin{array}{c}0.75 \%, \\
1.5 \% \\
2.0 \%\end{array}$ & $\begin{array}{l}5-125 \text { at an } \\
\text { interval of } 10\end{array}$ & $\begin{array}{l}200-800 \text { at an } \\
\text { interval of } 100\end{array}$ \\
\hline
\end{tabular}

For Parametric Study 2 only 


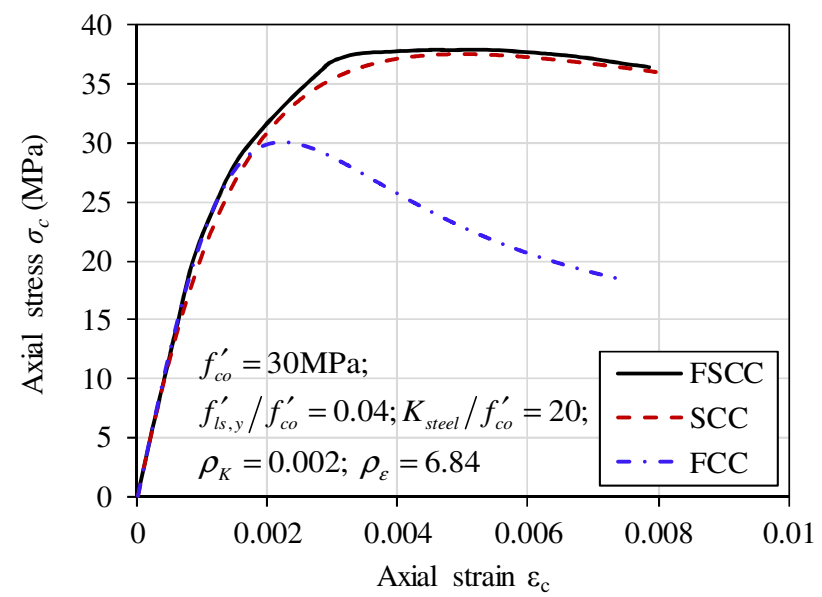

(a) Type I curve for FSCC

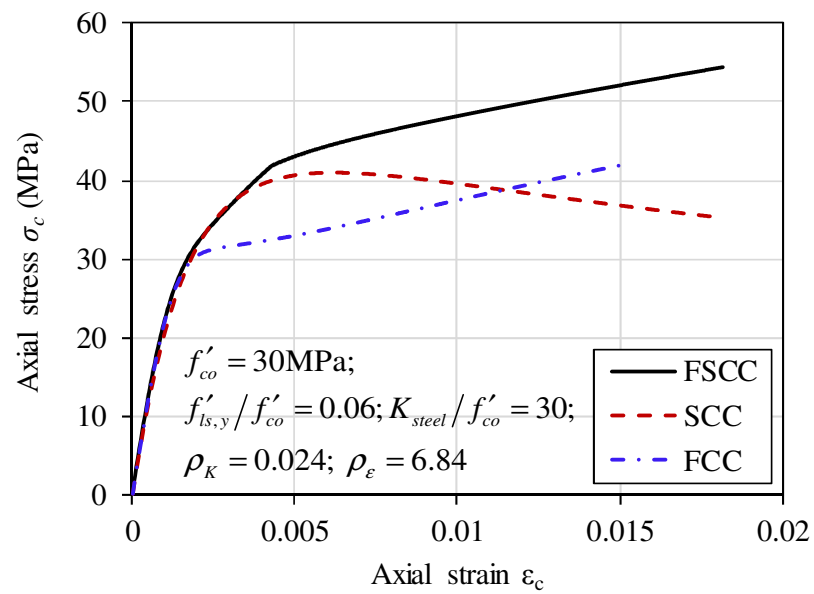

(b) Type II curve for FSCC

Figure 1 Typical stress-strain curves predicted using Teng et al.'s (2014) model

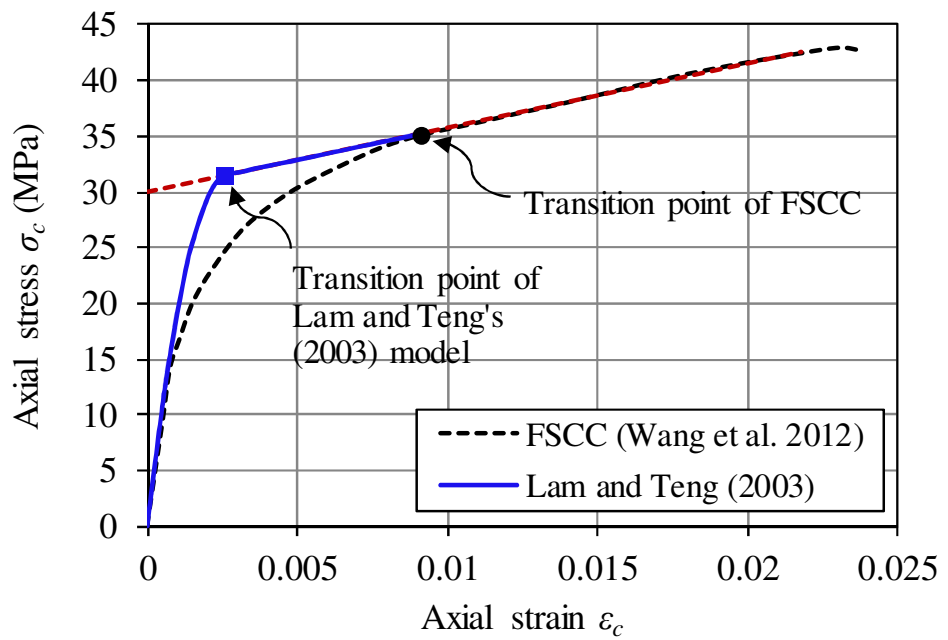

Figure 2 Performance of Lam and Teng's model for FSCC

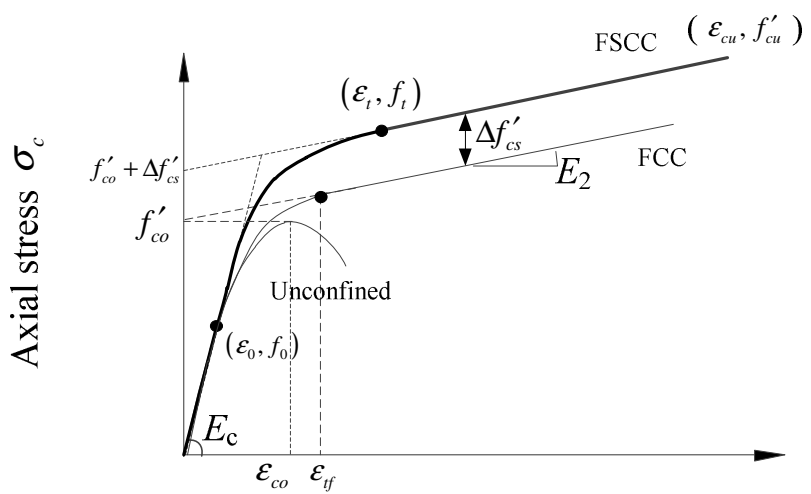

Axial strain $\varepsilon_{c}$

Figure 3 Proposed stress-strain model 


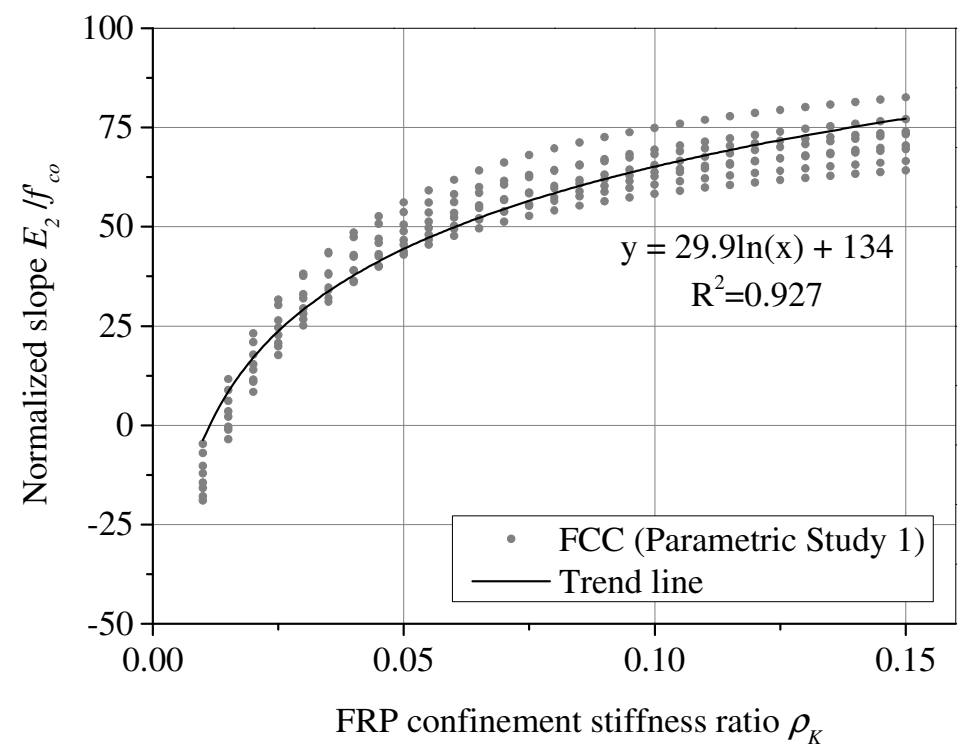

Figure 4 Effect of FRP confinement stiffness ratio on $E_{2}$

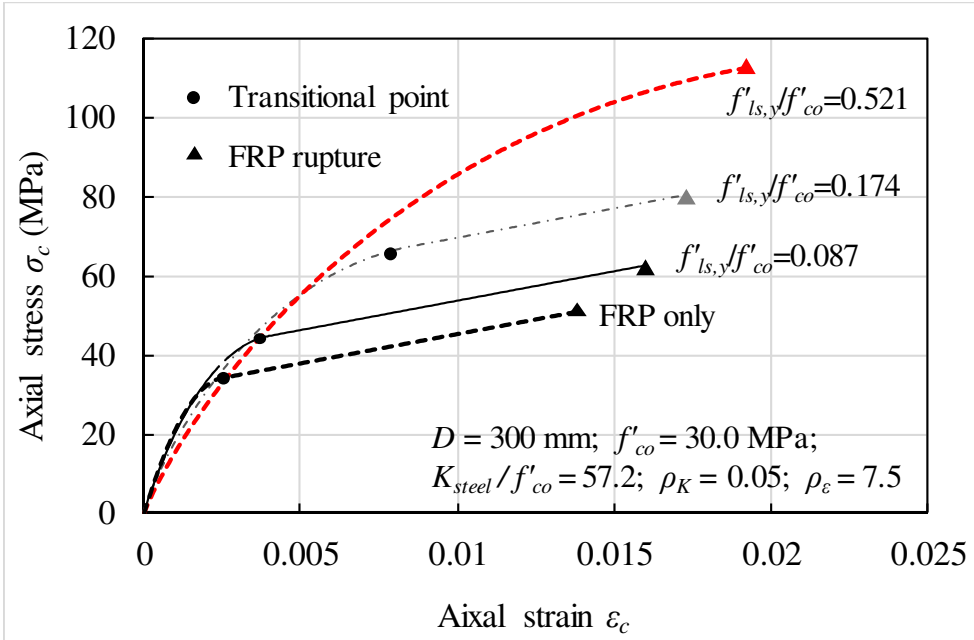

Figure 5 Effect of transverse steel on the transition point of stress-strain curve of FSCC 


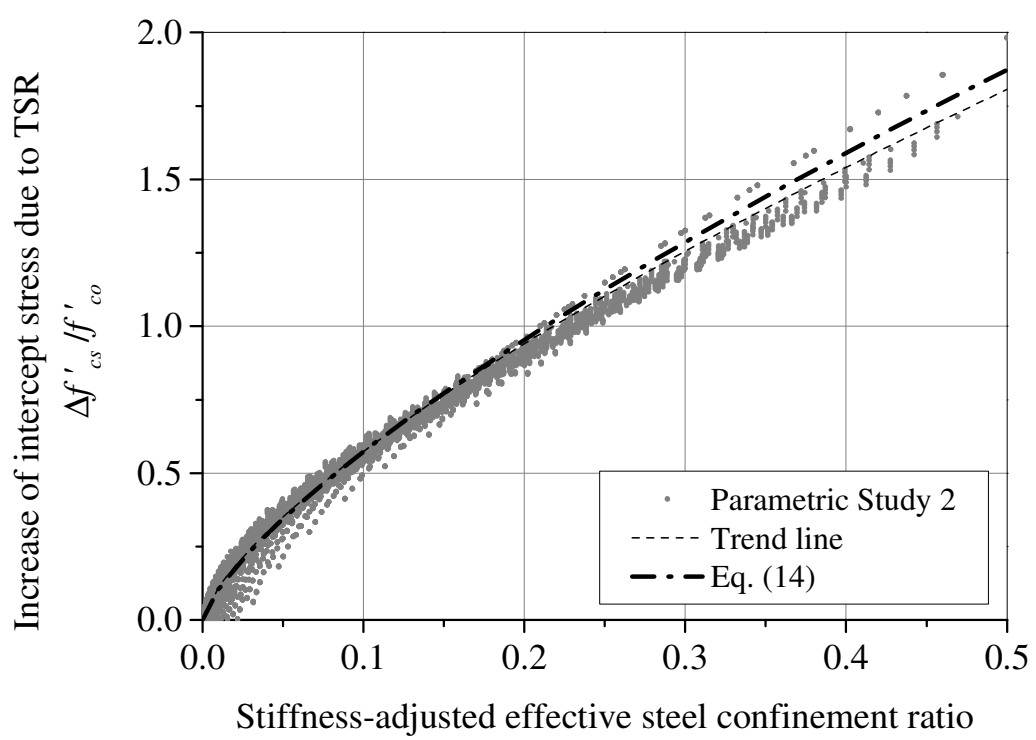

$$
f^{\prime}{ }_{l s, y} / f^{\prime}{ }_{c o} /\left(1+7.07 \rho_{f}^{1.60}\right)
$$

Figure 6 Increase of intercept stress due to TSR

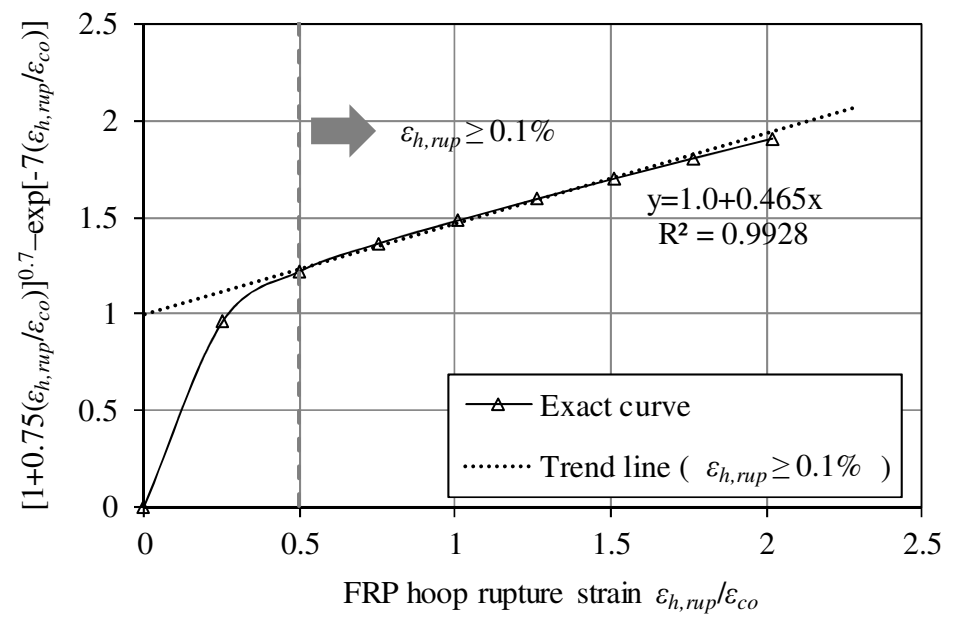

Figure 7 Simplification of Eq. (20) 


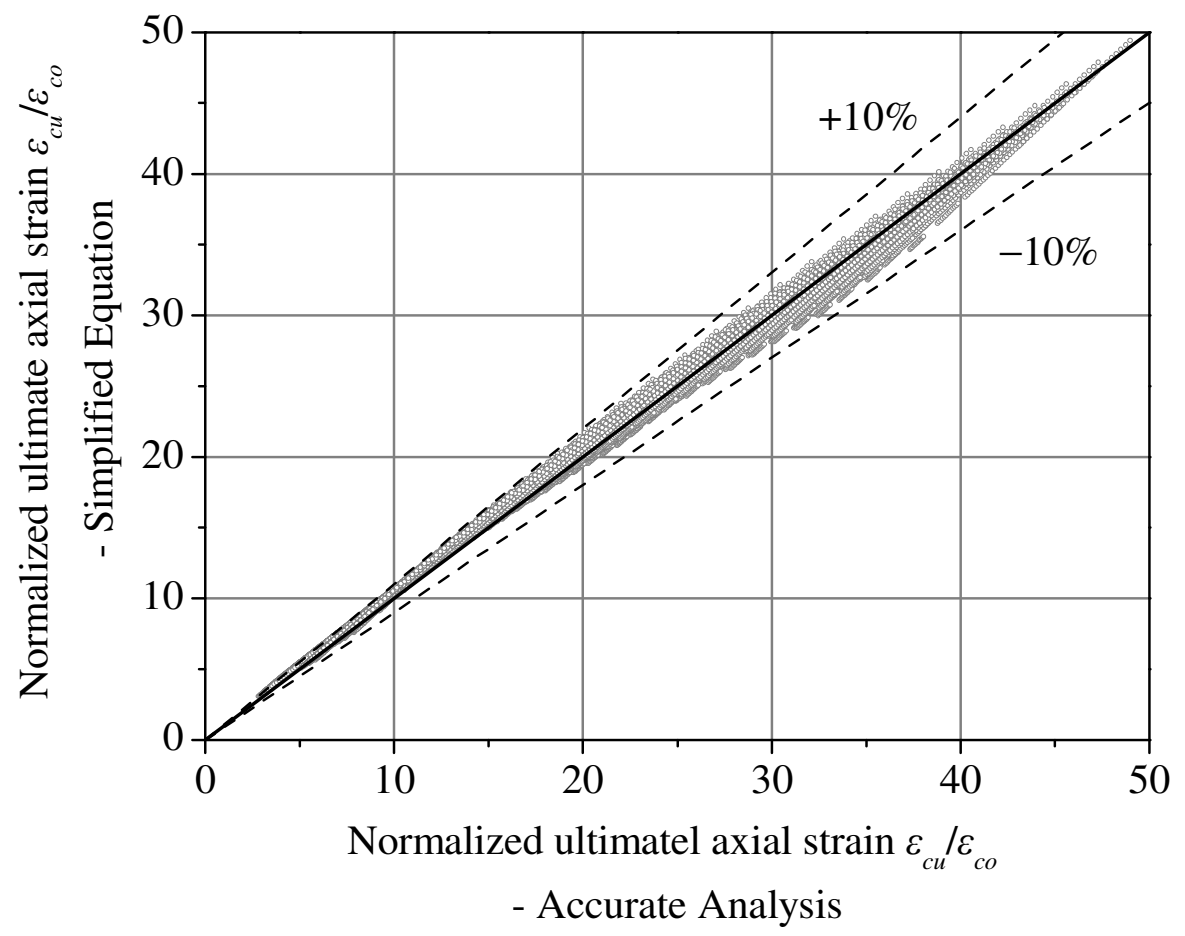

Figure 8 Performance of the proposed simplified equation for the ultimate strain

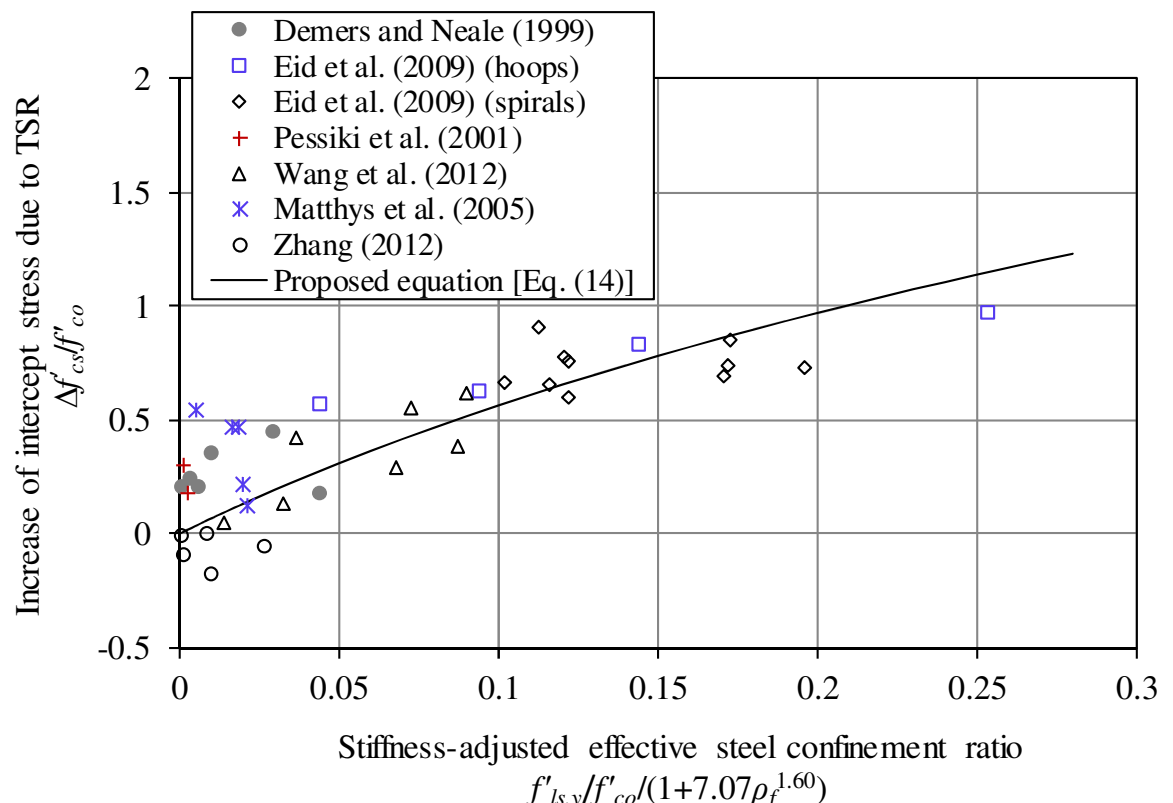

Figure 9 Performance of Eq. (14) for the prediction of the increase of intercept stress due to TSR 


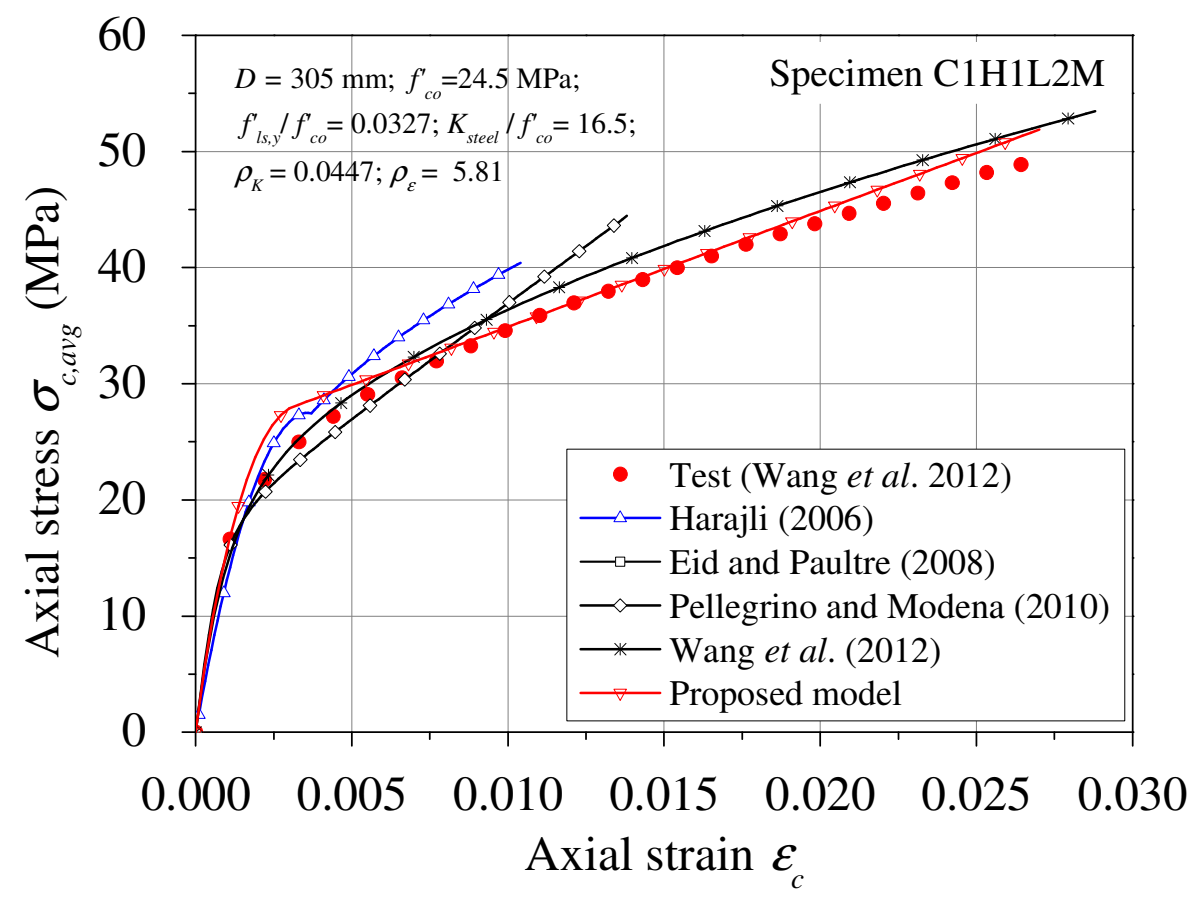

(a) Specimen C1H1L2M from Wang et al. (2012)

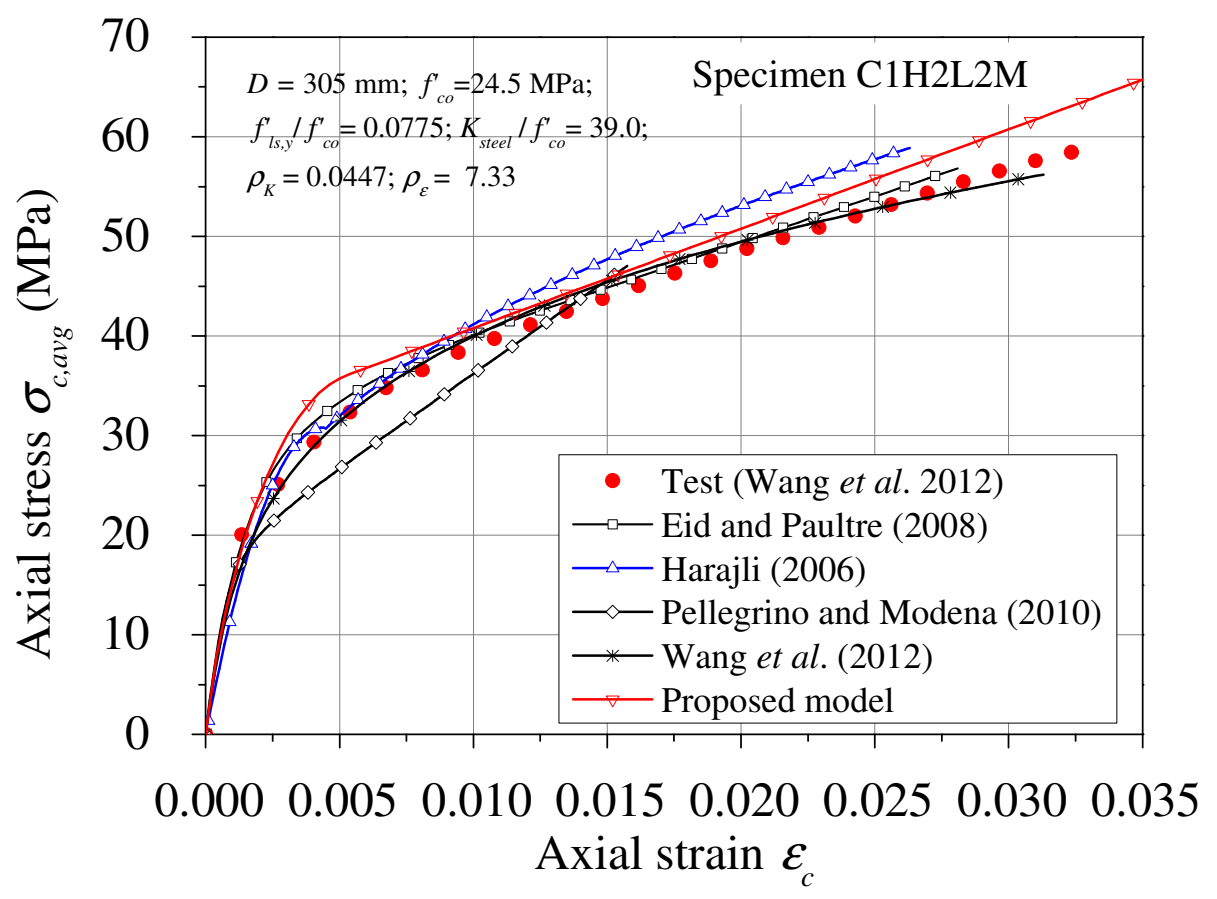

(b) Specimen C1H2L2M from Wang et al. (2012) 


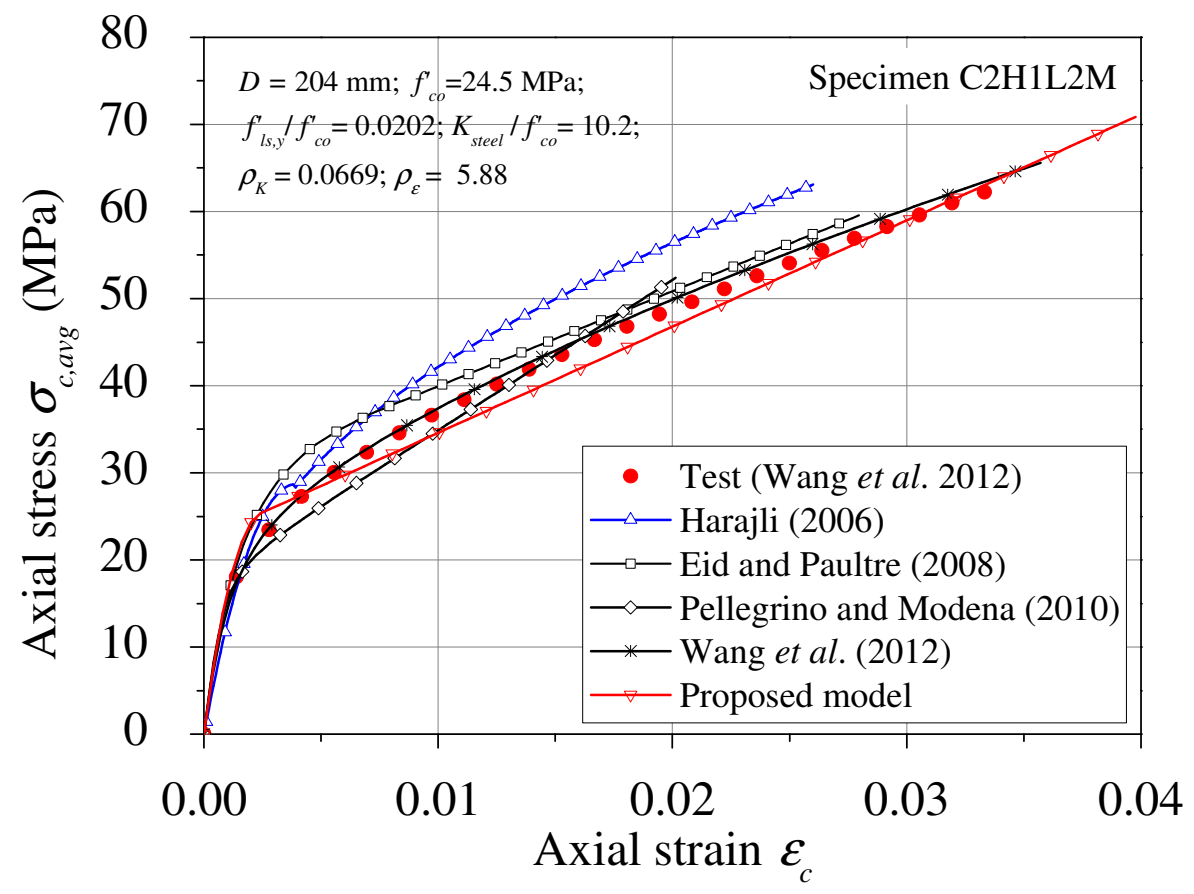

(c) Specimen C2H1L2M from Wang et al. (2012)

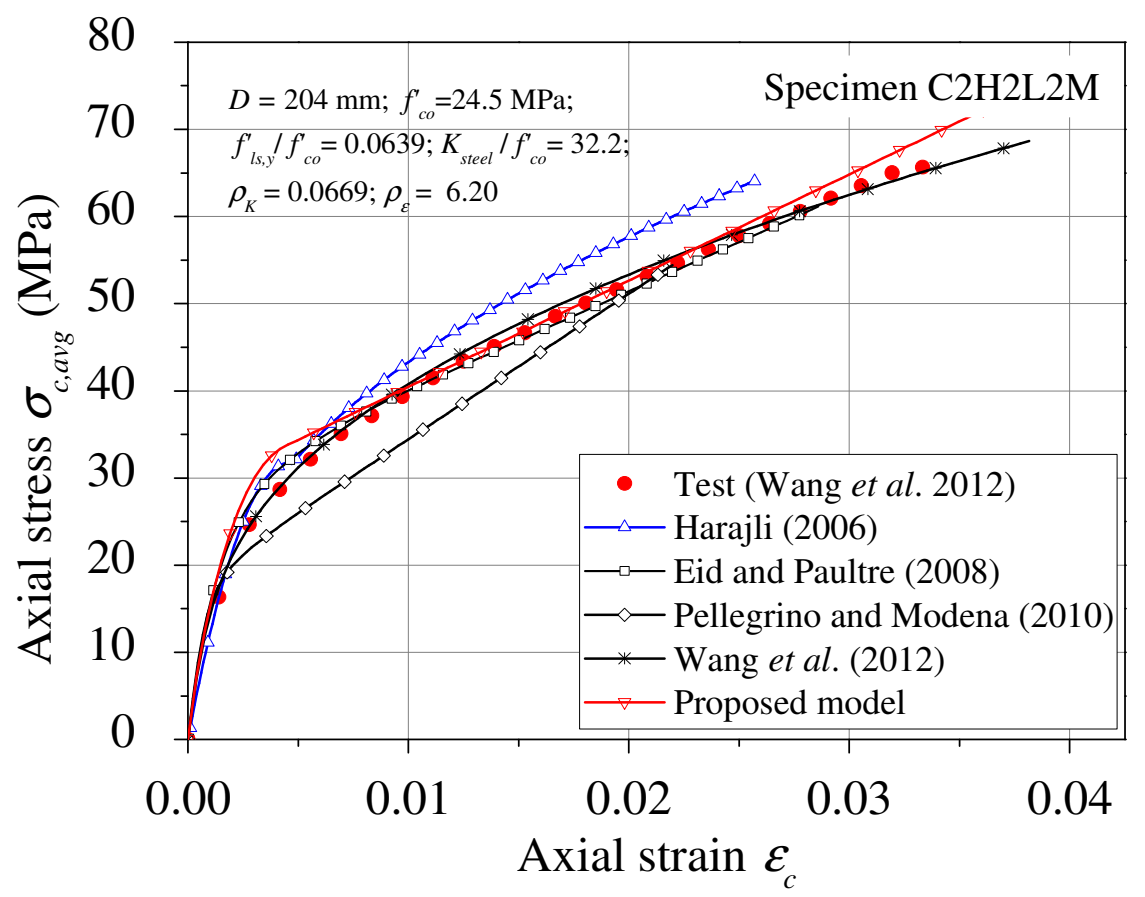

(d) Specimen C2H2L2M from Wang et al. (2012) 


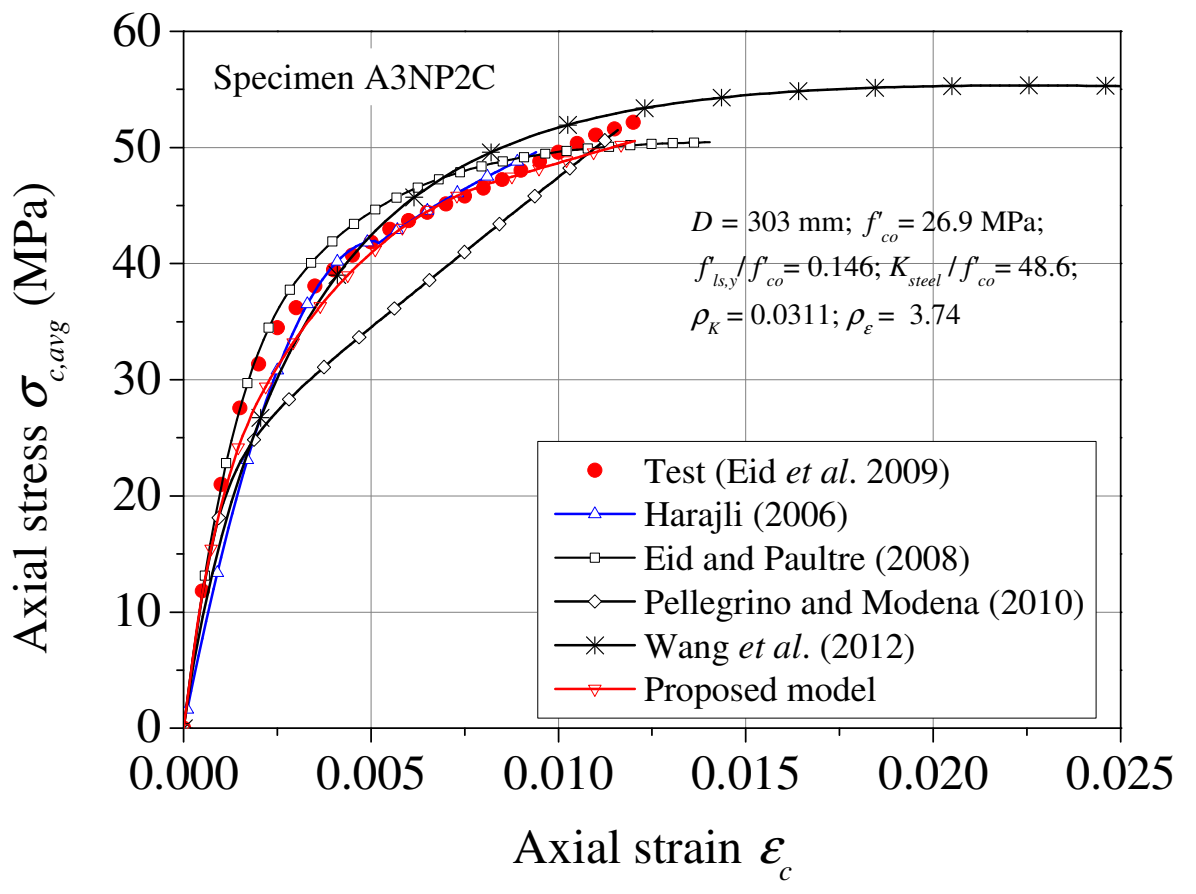

(e) Specimen A3NP2C from Eid et al. (2009)

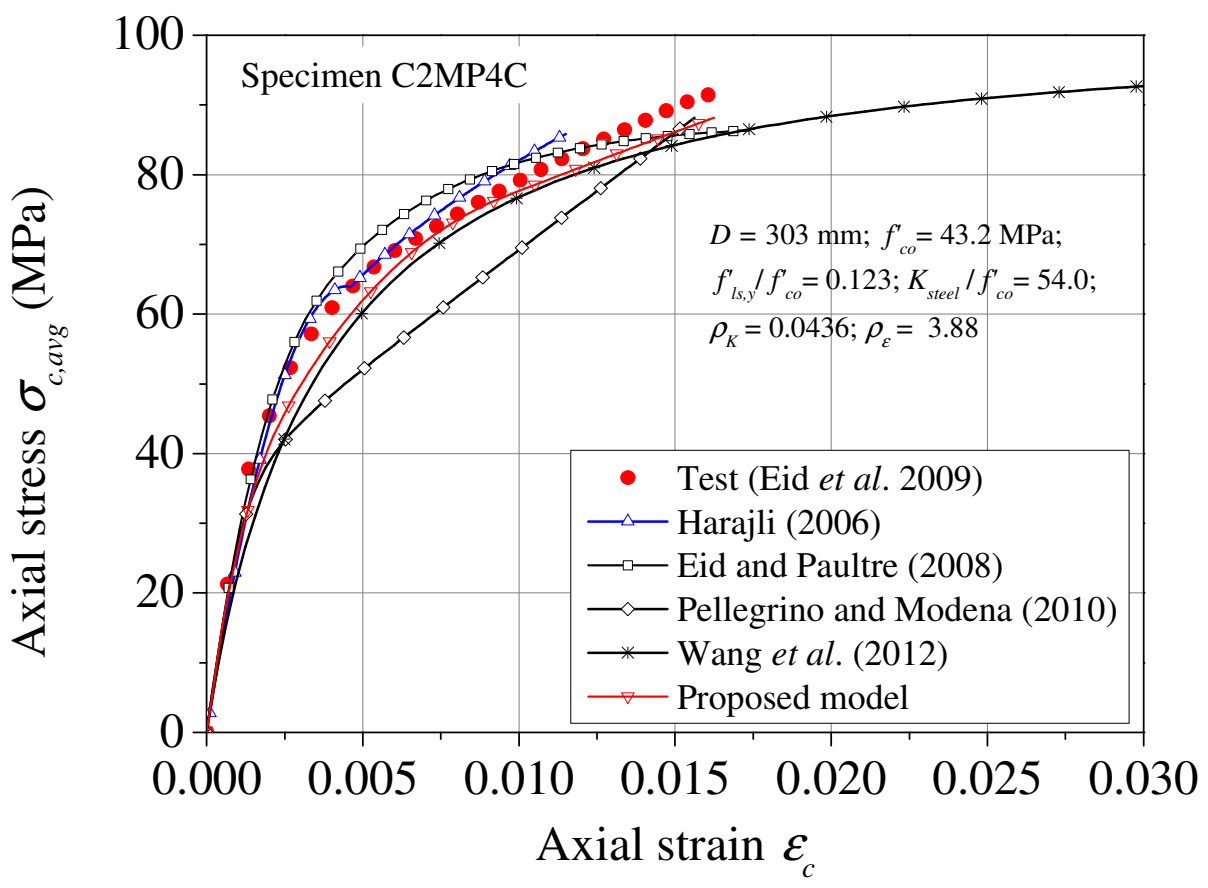

(f) Specimen C2MP4C from Eid et al. (2009) 


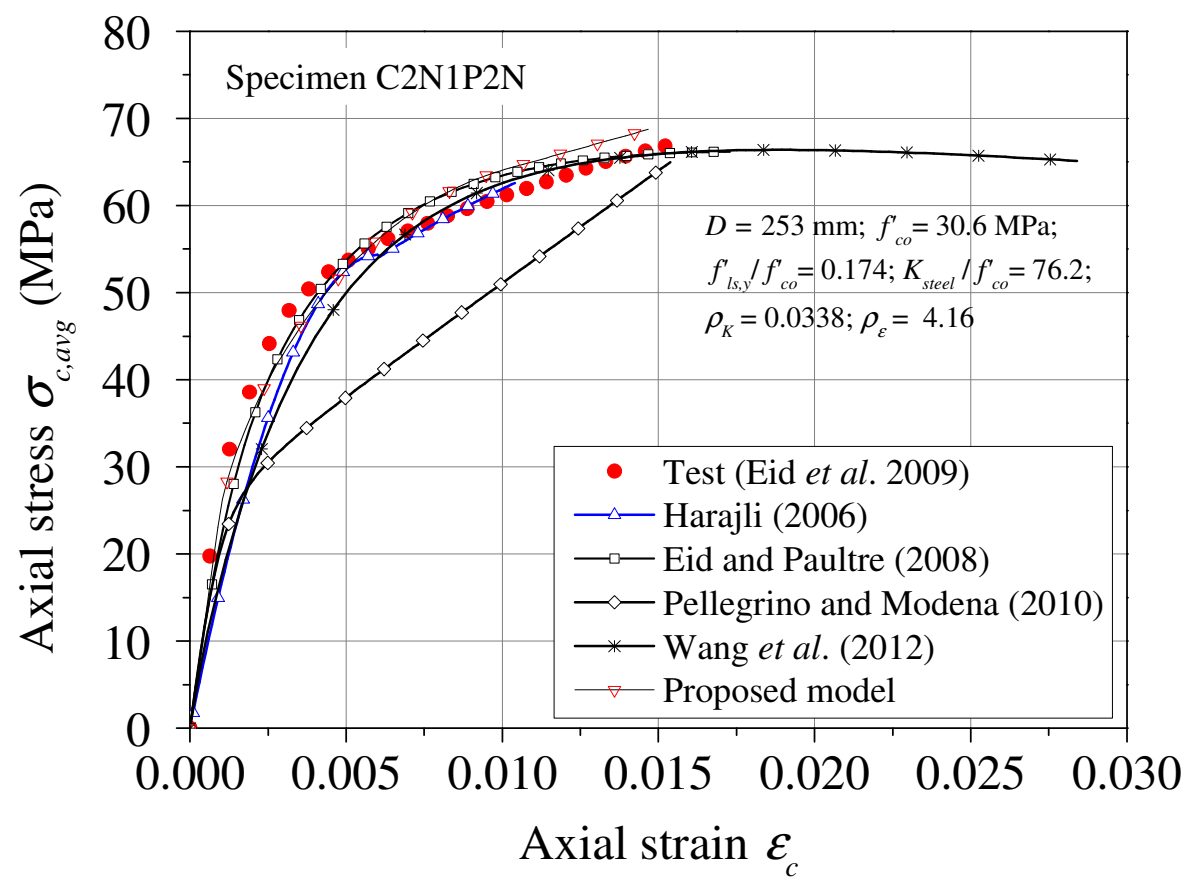

(g) Specimen C2N1P2N from Eid et al. (2009)

Figure 10 Performance of models for FSCC in FCRC columns tested by Wang et al. (2012) and Eid et al. (2009)

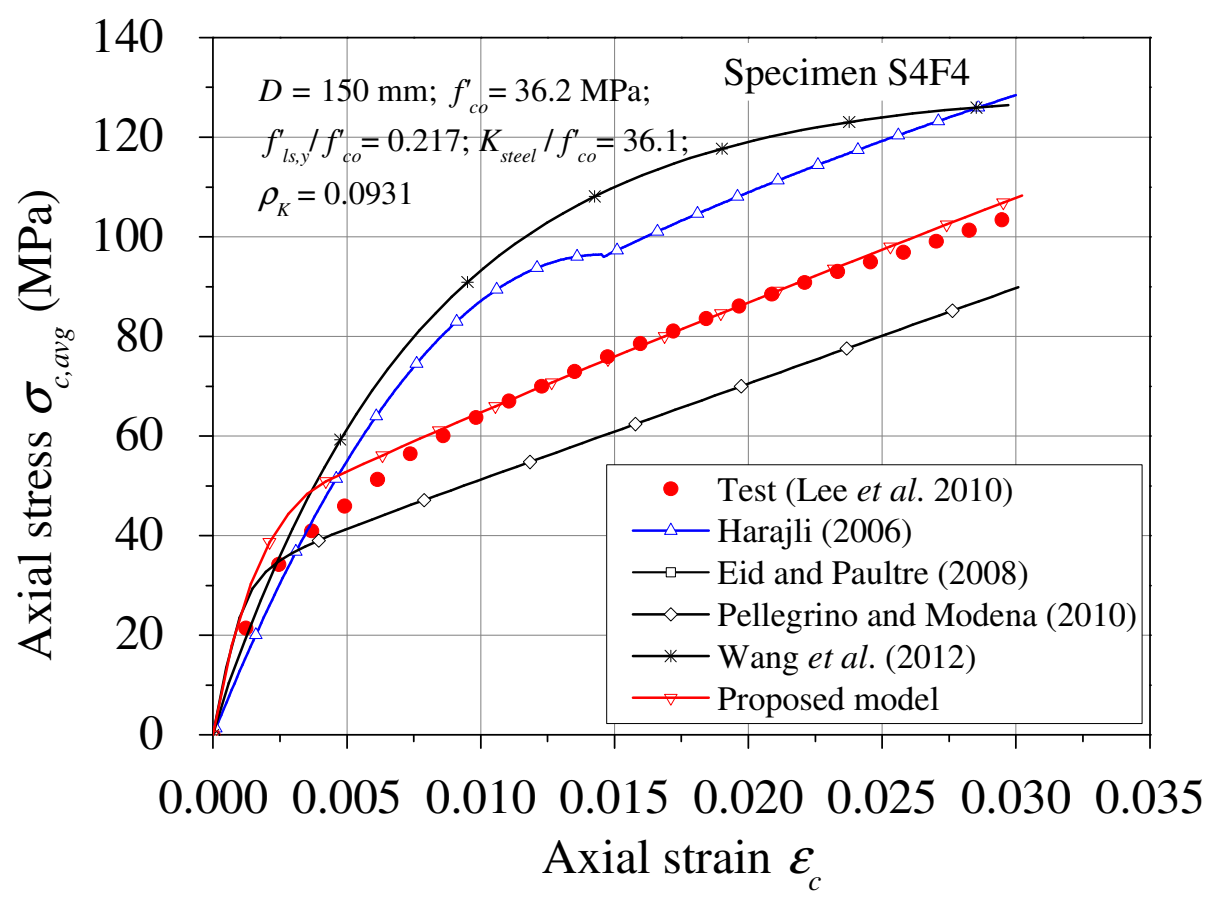

(a) Specimen S4F4 


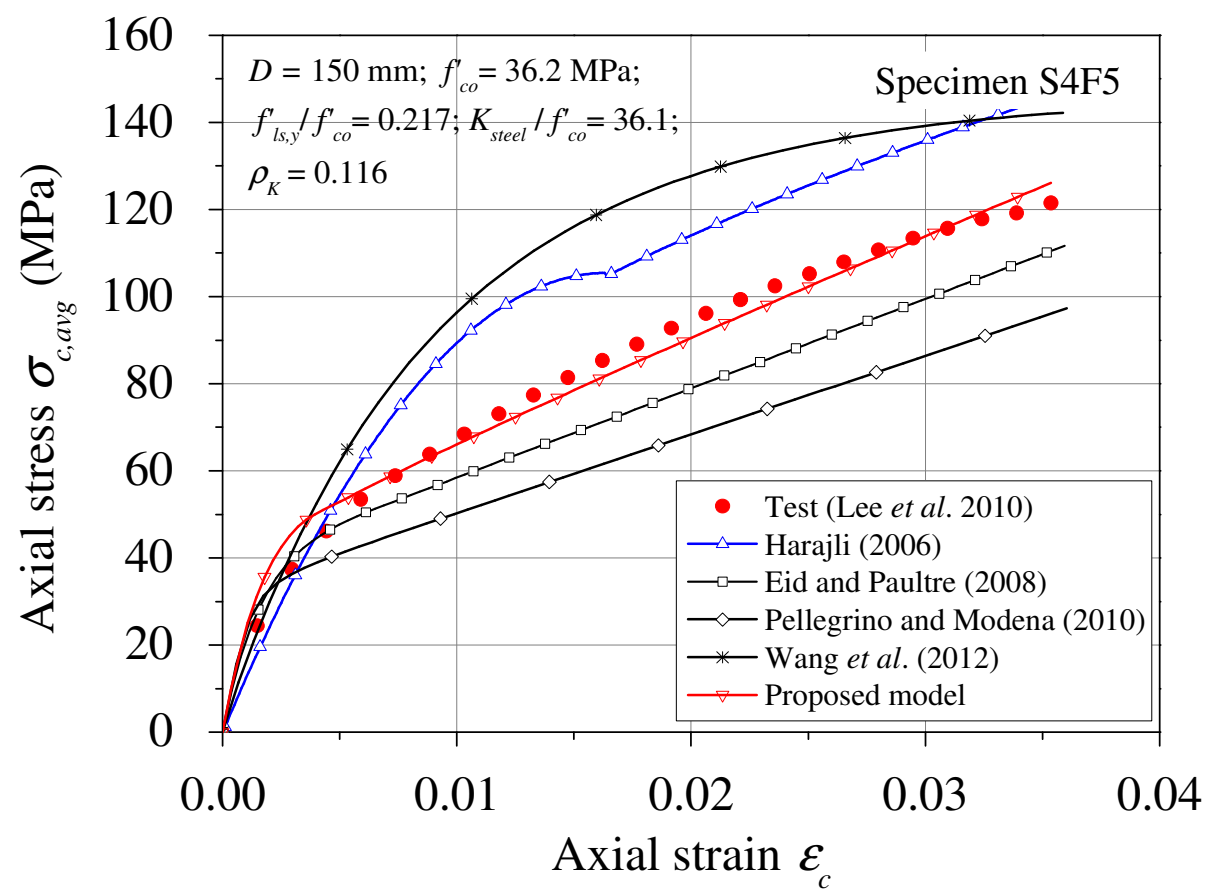

(b) Specimen S4F5

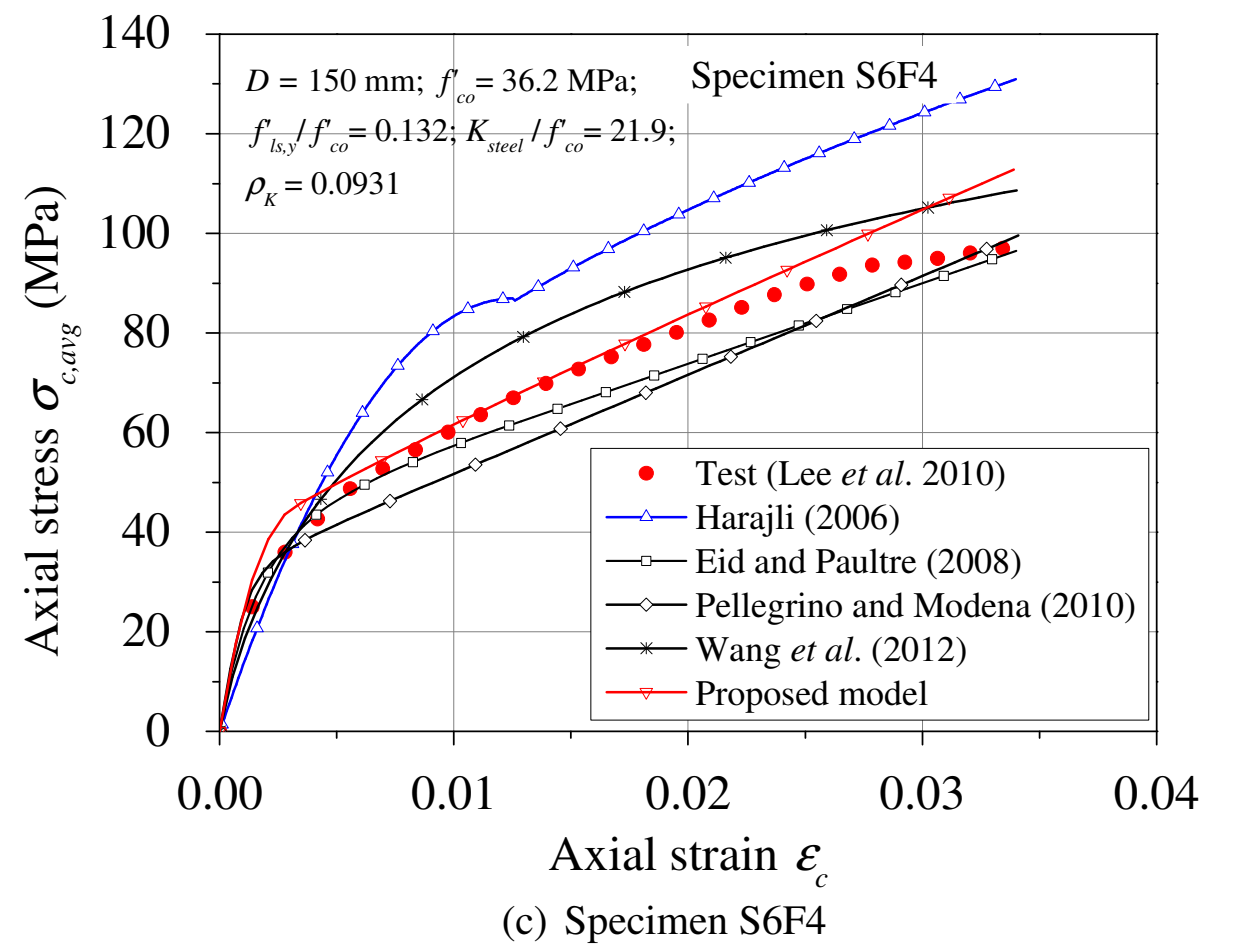




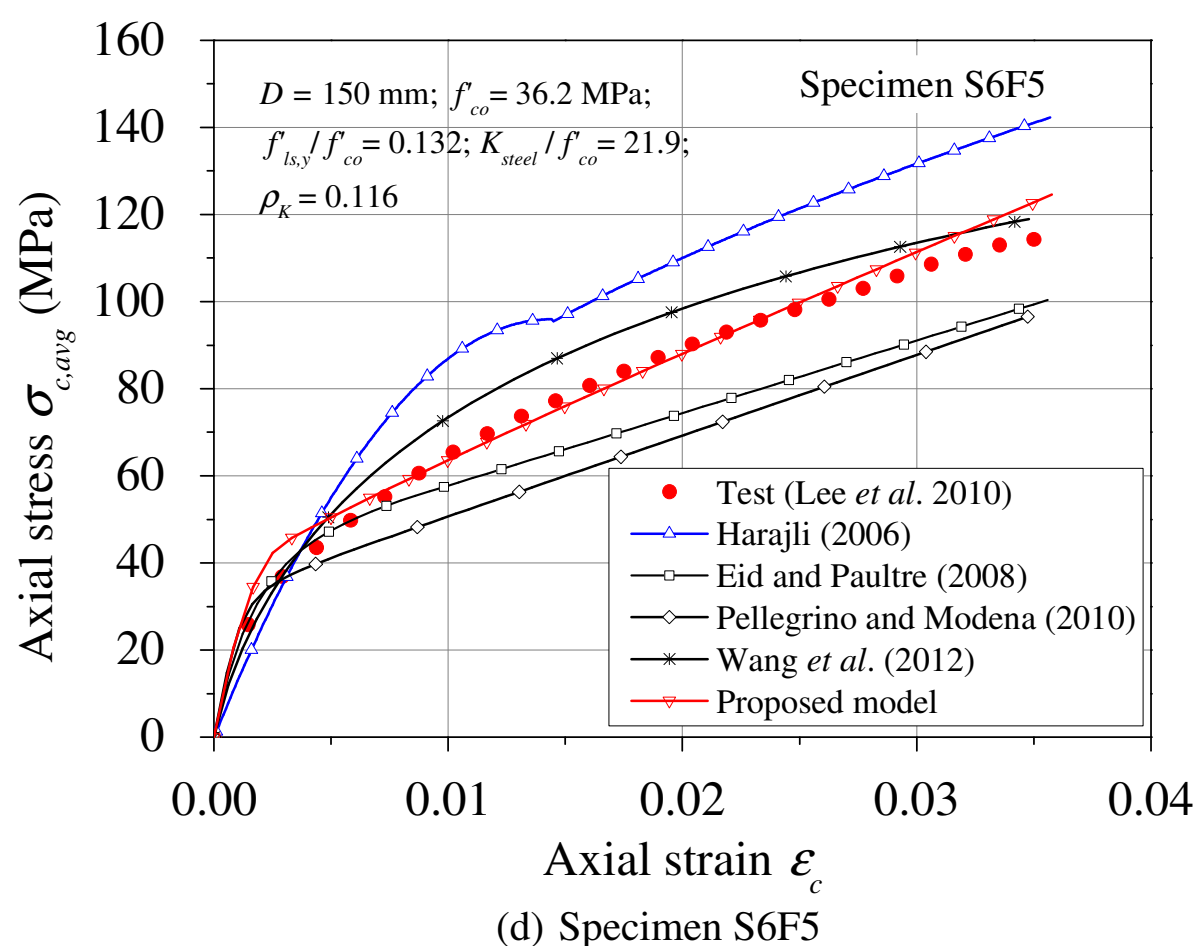

Figure 11 Performance of models for FSCC in FCRC columns tested by Lee $e t$ al. (2010)

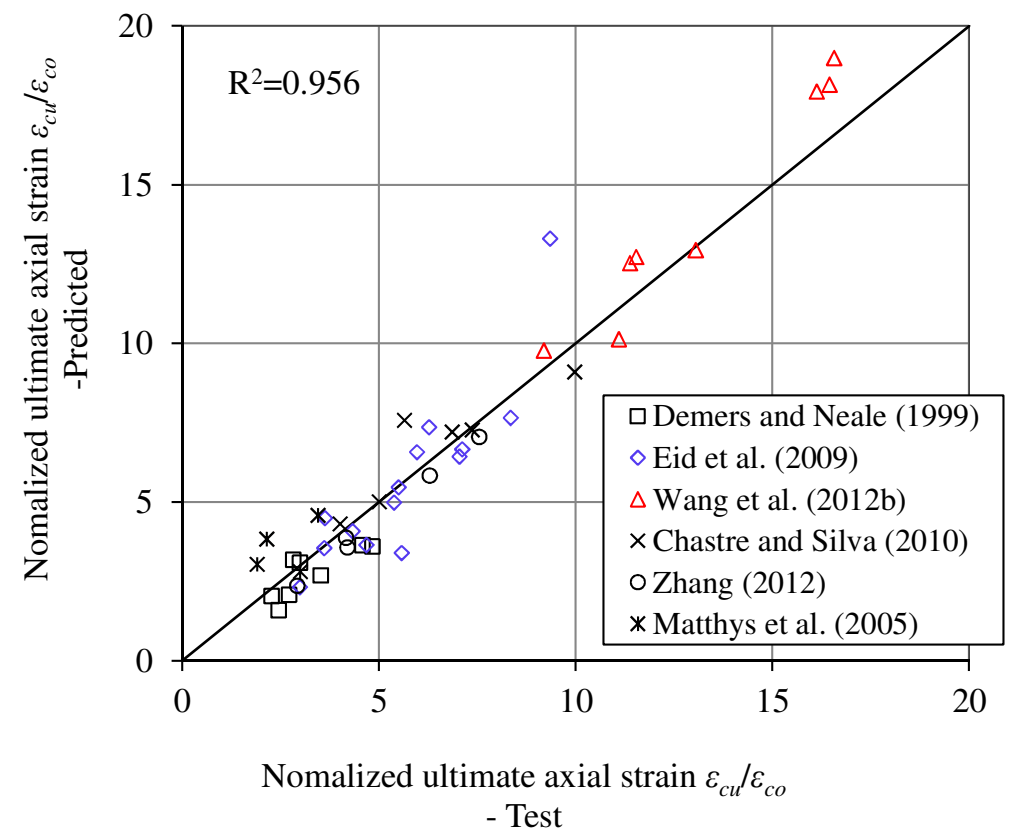

Figure 12 Performance of the proposed model in predicting the ultimate axial strain of FSCC 


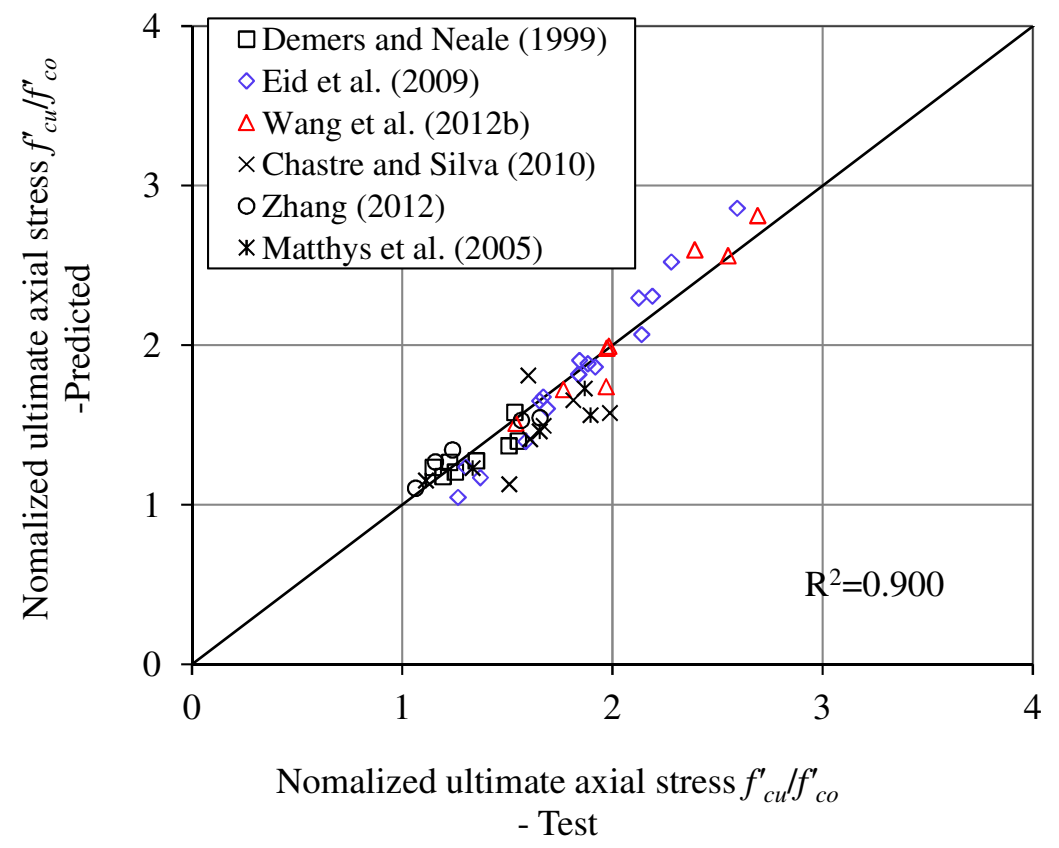

Figure 13 Performance of the proposed model in predicting the ultimate axial stress of FSCC 